Article

\title{
Effects of Low Concentration of Selected Analgesics and Successive Bioaugmentation of the Activated Sludge on Its Activity and Metabolic Diversity
}

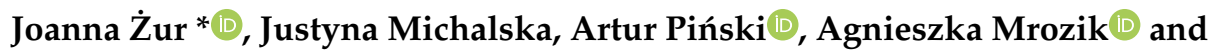 \\ Agnieszka Nowak *(D) \\ Institute of Biology, Biotechnology and Environmental Protection, Faculty of Natural Sciences, University of \\ Silesia in Katowice, Jagiellońska 28, 40-032 Katowice, Poland; jmichalska@us.edu.pl (J.M.); \\ apinski@us.edu.pl (A.P.); agnieszka.mrozik@us.edu.pl (A.M.) \\ * Correspondence: joanna.zur@us.edu.pl (J.Ż.); agnieszka.a.nowak@us.edu.pl (A.N.); \\ Tel.: +48-32-2009-462 (J.Ż.); +48-32-2009-576 (A.N.)
}

Received: 17 March 2020; Accepted: 13 April 2020; Published: 16 April 2020

\begin{abstract}
In this study, we evaluated the impact of the successive bioaugmentation of the activated sludge (AS) with the defined bacterial consortium on the activity and functional capacity of the AS microorganisms. In parallel, the removal of low concentrations of the selected non-steroidal anti-inflammatory drugs (ibuprofen, naproxen, diclofenac) and analgesic paracetamol was studied. We found that the addition of the bacterial consortium consisting of three pharmaceuticals-degrading strains Bacillus thuringiensis B1 (2015b), Stenotrophomonas maltophilia KB2, and Pseudomonas moorei KB4 into the AS did not cause any significant changes in the biomass abundance and metabolic activity of the AS microorganisms. Although, the successive bioaugmentation of the AS caused a slight increase in the metabolic diversity, the intensity of carbohydrates usage, and metabolic richness. Microorganisms in the bioaugmented and non-bioaugmented AS were able to degrade the mixture of the analyzed drugs with similar efficiency, however, diclofenac was removed more effectively in the bioaugmented AS. Several metabolites were identified and efficiently utilized, with the exception of 4-OH diclofenac. Two new diclofenac-degrading strains assigned as Serratia proteamaculans AS4 and Rahnella bruchi AS7 were isolated from the diclofenac-treated AS.
\end{abstract}

Keywords: activated sludge; bacterial consortium; bioaugmentation; biodegradation; functional capacity; non-steroidal anti-inflammatory drugs (NSAIDs); paracetamol; phylogenetic resolution

\section{Introduction}

A wide range of contaminants of emerging concerns (CEC), including pharmaceuticals and personal care products are continuously introduced into various environmental matrices. Organic pollutants are usually characterized by highly diversified structure, low water solubility, poor biodegradability, and environmental persistence [1,2]. Noteworthy, for most drugs, including the non-steroidal anti-inflammatory drugs (NSAIDs) and paracetamol, there are no strict monitoring recommendations or discharges guidelines. Pharmaceuticals used within this study, ibuprofen (IBU), naproxen (NPX), diclofenac (DCF), and paracetamol (APAP) have been detected in several natural matrices, e.g., surface water [3,4], wastewater [5], soil and sludge [6-8] at a concentration range from ng $\mathrm{L}^{-1}$ to $\mu \mathrm{g} \mathrm{L}^{-1}$. Drugs remain active even at low concentrations, therefore, their presence may lead to successive deterioration of water quality and have an adverse impact on the ecosystem and human health [9]. The main sources of pharmaceuticals in the environment include domestic and industrial wastewater from pharmaceuticals production, hospital effluents, landfill leachate, 
artificial recharge using reclaimed water, and infiltration of contaminated water from agricultural land. To date, the conventional methods i.e., chlorination as well as the advanced treatment techniques e.g., the membrane bioreactors, nanofiltration, reverse osmosis, and carbon nanocomposites with magnetic properties are not fully adapted for pharmaceuticals removal $[2,9,10]$. Moreover, some authors pointed out that the biological treatment is a bottleneck for micro-pollutant removal [11].

The efficiency of analgesics biodegradation by conventional activated sludge (AS) and membrane bioreactors was summarized by Tiwari et al. [9], who found almost $90 \%-100 \%$ removal efficiency of IBU but only 55\%-85\% and 5\%-45\% removal efficiencies of NPX and DCF, respectively. The effectiveness of the AS treatment can be further improved by bioaugmentation, however, the successful treatment depends primarily on the behavior of the strains introduced to the environment, which are characterized by the potential to alter the interplay within the native communities resulting in strong shifts in their structure, with neutral, beneficial, or detrimental impacts. The behavior of the exogenous strains introduced into the AS depends on their ability to survive and grow within the new habitat, compete with autochthonous microorganisms for the acquisition of nutrients, and resilience to the changing environmental conditions such as $\mathrm{pH}$, temperature, and water availability [12]. The successive bioaugmentation, which partly mitigates those problems, is based on the repetitive introduction of highly competent and carefully selected bacteria, whose growth rate exceeds washout and predation [13-16].

Some authors pointed out that microorganisms of one species may be replaced by others with the same metabolic properties [17]. Indeed, most basic functions i.e., respiration, nutrient uptake, or denitrification are rather constant and unrelated to microbial diversity. Contrary, processes carried out by more specialized strains i.e., xenobiotics removal or detoxification, are vulnerable to microbial diversity decrease. Environments subjected to the continuous influence of xenobiotics constitute a valuable source of new isolates with increased metabolic properties [17]. Up to now, the number of microorganisms capable of degrading the NSAIDs is limited, thus, there is an urgent need to isolate new bacterial strains, especially those capable of utilizing polycyclic drugs characterized by poor biodegradability, i.e., DCF and NPX [10,18]. In recent years, many authors highlighted that biodegradation of xenobiotics by pure bacterial cultures fails to reflect the adequate behavior of environmental microorganisms during xenobiotics degradation, mainly due to the synergistic metabolic activities exhibited by microorganisms in communities. Thus, bioaugmentation based on microbial consortia, where degradation processes are frequently dependent on the combined actions of various species, is more often applied for the degradation of xenobiotic compounds with low susceptibility to biodegradation. A combination of strains may be used to mimic naturally occurring communities, enhance or imitate a degradation pathway, or degrade several target pollutants within the same wastewater [19,20]. Zhang et al. [21] noticed that the microbial consortium used for APAP degradation achieved higher removal rates and significantly better tolerance to APAP with a shorter adaptation time. One of the crucial issues related to the degradation processes carried out by microorganisms concerns the environmental concentrations, which are frequently much lower than doses used in lab-scale degradation experiments. It must be taken into consideration that there are threshold concentrations of xenobiotics necessary to induce catabolic enzymes, below which degradation is unperceived. Moreover, the differences in the kinetics of the same biodegradation processes, but with different concentrations of substrate and competition from other carbon sources at low levels are frequently observed [22,23].

Thus, the aim of this study included the following goals: (i) analyzing the impact of low analgesics concentrations of $0.5 \mathrm{mg} \mathrm{L}^{-1}$ for NPX and DCF and $1 \mathrm{mg} \mathrm{L}^{-1}$ for IBU and APAP on the AS microorganisms, (ii) establishing the influence of introduced microorganisms on the autochthonous microflora, (iii) estimating the effectiveness of analgesics removal assisted by the consortium of bacterial strains, (iv) studying the degradation processes and formation of secondary metabolites, and (v) isolating new bacterial strains able to degrade DCF. 


\section{Materials and Methods}

\subsection{Characteristics of the Activated Sludge}

The AS was derived from the aerobic chamber of the wastewater treatment plant (WWTP) Klimzowiec located in Chorzów, Poland. The AS characterization included determinations of $\mathrm{pH}$, sludge volume index (SVI), and mixed liquor suspended solids (MLSS) [24]. The microbial activity in the AS was assayed via the quantification of the dehydrogenases (DHA) [25], nonspecific esterases (NSEA) [26], and specific oxygen uptake rate (SOUR) [27]. The number of total heterotrophic bacteria (THB) in the AS was determined after their extraction from the sludge [16] and enumerated according to EN ISO 8199:2010 [28] (Table 1). The part of the AS was sterilized (three times at 3 day intervals, $121{ }^{\circ} \mathrm{C}, 40 \mathrm{~min}$ ) for further analysis. Our preliminary studies indicated that autoclaving in such conditions allowed to obtain sterile sludge, which was also confirmed by serial dilution plating.

Table 1. Characteristics of the activated sludge (AS) obtained from the Klimzowiec sewage plant.

\begin{tabular}{cc}
\hline Parameter & Value \\
\hline $\mathrm{pH}$ & $7.713 \pm 0.071$ \\
$\mathrm{SVI}, \mathrm{g} \mathrm{cm}$ & $114.182 \pm 1.665$ \\
$\mathrm{MLSS}^{-3} \mathrm{~g} \mathrm{~L}^{-1}$ & $3.667 \pm 0.180$ \\
$\mathrm{SOUR}, \mathrm{mg} \mathrm{O}_{2} \mathrm{~g}^{-1} \mathrm{MLSS} \mathrm{h}^{-1}$ & $8.424 \pm 0.621$ \\
$\mathrm{DHA}, \mathrm{mg} \mathrm{TPF} \mathrm{g}^{-1} \mathrm{MLSS} \mathrm{h}^{-1}$ & $16.096 \pm 0.952$ \\
NSEA, $\mu$ g fluorescein g $\mathrm{MLSS} \mathrm{h}^{-1}$ & $23.012 \pm 0.697$ \\
Number of the THB, $\log \mathrm{CFU} \mathrm{g}^{-1} \mathrm{MLSS}^{-1}$ & $8.226 \pm 0.992$ \\
\hline
\end{tabular}

\subsection{Composition of Bacterial Consortium}

The microbial consortium used for bioaugmentation of the AS included three environmental bacterial strains: Bacillus thuringiensis B1 (2015b), Stenotrophomonas maltophilia KB2, and Pseudomonas moorei KB4 derived from the Microbial Culture Collection in the Institute of Biology, Biotechnology and Environmental Protection (Faculty of Natural Sciences, University of Silesia in Katowice, Poland). All of the strains can degrade the selected NSAIDs: IBU, NPX, DCF, and analgesic drug, APAP (Table 2). In preliminary studies, the most effective bacterial consortium with the appropriate proportions of the particular bacterial strains was established. According to the obtained results, the initial optical density of particular bacteria in the inoculum at a wavelength of $600 \mathrm{~nm}\left(\mathrm{OD}_{600}\right)$ was leveled-off to 0.1 , which corresponded with $2.7 \times 10^{5}, 1.6 \times 10^{7}$, and $1.7 \times 10^{6} \mathrm{CFU} \mathrm{mL}^{-1}$ for B1 strain, KB2 strain, and KB4 strain, respectively.

Table 2. Composition of the bacterial consortium for bioaugmentation of the AS.

\begin{tabular}{cccc}
\hline Bacterial Strain & Site of Isolation & Degradation of Aromatics & Reference \\
\hline $\begin{array}{c}\text { Bacillus thuringiensis } \\
\text { B1(2015b) }\end{array}$ & $\begin{array}{c}\text { Contaminated soil } \\
\text { Jaworzno, Poland }\end{array}$ & Ibuprofen, naproxen & [29] \\
\hline $\begin{array}{c}\text { Stenotrophomonas } \\
\text { maltophilia KB2 }\end{array}$ & $\begin{array}{c}\text { Activated sludge } \\
\text { Miechowice, Poland }\end{array}$ & $\begin{array}{c}\text { Naproxen, phenol, } \\
\text { mononithrophenols, } \\
\text { methylphenols }\end{array}$ & [30] \\
\hline Pseudomonas moorei KB4 & $\begin{array}{c}\text { Activated sludge } \\
\text { Chorzów, Poland }\end{array}$ & $\begin{array}{c}\text { Paracetamol, diclofenac, phenol, } \\
\text { 4-hydroxybenzoic acid }\end{array}$ & [31] \\
\hline
\end{tabular}

\subsection{Experimental Set-Up and Isolating Diclofenac-Degrading Strains}

Before the experiment, the AS was diluted with the synthetic wastewater (SW) medium with the following composition, $\mathrm{g} \mathrm{L}^{-1}$ : $0.285 \mathrm{C}_{6} \mathrm{H}_{12} \mathrm{O}_{6} ; 0.69 \mathrm{CH}_{3} \mathrm{COONa} ; 0.145 \mathrm{NH}_{4} \mathrm{Cl} ; 0.06 \mathrm{KH}_{2} \mathrm{PO}_{4}$; $0.04 \mathrm{~K}_{2} \mathrm{HPO}_{4} ; 0.069 \mathrm{NaCl} ; 0.026 \mathrm{CaCl}_{2}$ and $0.145 \mathrm{KCl}$ [16] to obtain the initial concentration of the sludge biomass of $3.0 \pm 0.5 \mathrm{~g} \mathrm{~L}^{-1}$, which reflected the average concentration of microorganisms 
desirable for the wastewater treatment process. The composition of the SW reflected the ratio of carbon, nitrogen, and phosphorus in the effluents of the WWTP Klimzowiec.

Herein, six experimental conditions of the AS (assays) were designed (Figure 1A). The abiotic control of the analgesics physicochemical decomposition was analyzed in the control SWc assay, which was filled with the SW supplemented with the same doses of examined pharmaceuticals as the other systems. The AS1 assay contained the AS supplemented with the NSAIDs, APAP, and bacterial consortium. The assay AS2 was non-bioaugmented but fed with the NSAIDs and APAP. The AS3 contained sterilized AS with NSAIDs, APAP, and bacterial consortium. The assay assigned as AS4 served as the bioaugmented biotic control and contained the AS with bacterial consortium, while the AS5 served as the non-bioaugmented biotic control. The experiment was conducted for 30 days at $23{ }^{\circ} \mathrm{C}$ with mixing. Every 7 days, the volume of the supernatant liquid was measured and replaced with fresh SW which reflected the natural cycles occurring in the WWTP. The bacterial consortium was introduced repeatedly every 7 days after the exchange of supernatant liquid to avoid inoculated bacteria being washed out from the AS system. The AS was amended with the mixture of IBU $\left(1 \mathrm{mg} \mathrm{L}^{-1}\right), \operatorname{APAP}\left(1 \mathrm{mg} \mathrm{L}^{-1}\right), \mathrm{NPX}\left(0.5 \mathrm{mg} \mathrm{L}^{-1}\right)$, and DCF $\left(0.5 \mathrm{mg} \mathrm{L}^{-1}\right)$. Every 7 days after the medium exchange, the new doses of drugs were spiked to the appropriate initial concentrations. We measured the concentration of the pharmaceuticals residue before the medium exchange to correctly spike drugs to the assays and after the addition to verify that the proper concentration of the drugs was introduced. The pharmaceutical removal was monitored in the 7-day time regime mimicking the operation of the WWTPs.

A

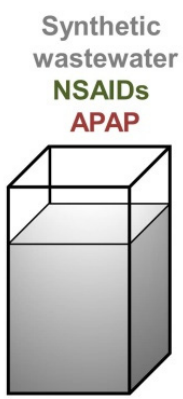

SWc

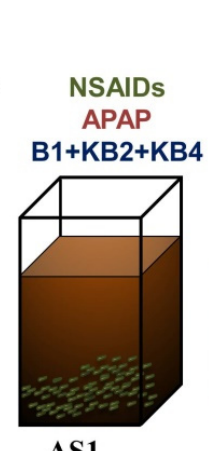

AS1



AS2
Sterilized AS NSAIDs APAP $\mathrm{B} 1+\mathrm{KB} 2+\mathrm{KB} 4$

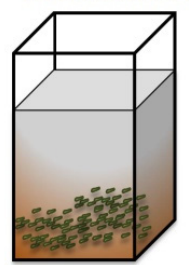

AS3
Non-

bioaugmented

biotic control

without NSAIDs

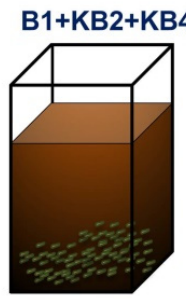

AS4

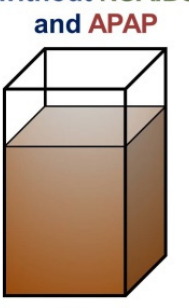

AS5

Assays

Analyses:

- dehydrogenases activity

- chemical oxygen demand (COD)

- Total Heterotrophic Bacteria (THB)

- functional capacity

- biomass evaluation

- removal of analgesics
B

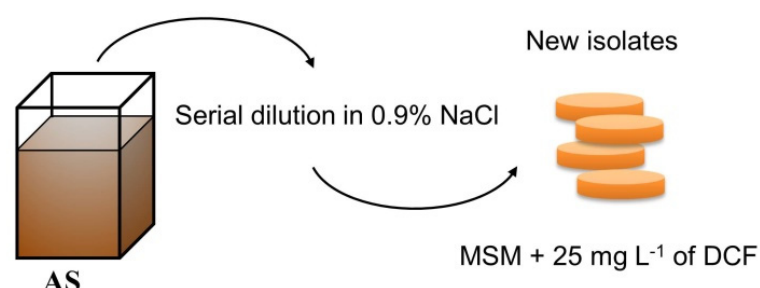

Figure 1. Scheme of the experimental set-up. (A) Different non- or bioaugmented assays AS1-AS4 fed with NSAIDs and APAP and control assay AS5, (B) scheme of the isolation of new DCF-degrading strains from the DCF-treated AS by classical enrichment technique. NSAIDs-non-steroidal anti-inflammatory drugs (IBU, NPX, and DCF); IBU—ibuprofen, NPX—naproxen, DCF—diclofenac, APAP—paracetamol.

Parallelly, new bacterial strains able to degrade DCF were isolated from the AS not subjected to bioaugmentation using the classical enrichment technique [29]. Briefly, $10 \mathrm{~mL}$ of the AS was introduced into $90 \mathrm{~mL}$ of $0.9 \% \mathrm{NaCl}$ and supplemented with DCF at a concentration of $10 \mathrm{mg} \mathrm{L}^{-1}$ as a sole carbon and energy source. The culture was incubated at $23^{\circ} \mathrm{C}$ with shaking $(130 \mathrm{rpm})$ for 5 weeks. If the complete degradation of DCF was achieved, a higher dose of the drug was introduced. After the adaptation of the AS microorganisms to $25 \mathrm{mg} \mathrm{L}^{-1}$ of DFC, $1 \mathrm{~mL}$ of sample was serially diluted from 
$10^{-1}$ to $10^{-3}$ with the $\mathrm{NaCl}$ and spread onto the agar plates containing mineral salts medium (MSM) with the following composition, $\mathrm{g} \mathrm{L}^{-1}$ : $3.78 \mathrm{Na}_{2} \mathrm{HPO}_{4} \times 12 \mathrm{H}_{2} \mathrm{O} ; 0.5 \mathrm{KH}_{2} \mathrm{PO}_{4} ; 5.0 \mathrm{NH}_{4} \mathrm{Cl} ; 0.2 \mathrm{MgSO}_{4} \times$ $7 \mathrm{H}_{2} \mathrm{O} ; 0.01$ yeast extract [32] supplemented with $25 \mathrm{mg} \mathrm{L}^{-1}$ of DCF to obtain pure bacterial cultures. The agar plates were incubated at $23^{\circ} \mathrm{C}$ for $24 \mathrm{~h}$, and single colonies were further proliferated on the nutrient agar for the purity tests (Figure 1B).

\subsection{Evaluating the Activated Sludge Quality and Impact of Bioaugmentation}

To estimate the metabolic response and functional capacity of microorganisms from the repeatedly bioaugmented AS as well as the condition of the non-bioaugmented AS, several different parameters were measured.

\subsubsection{Measuring the Dehydrogenases Activity}

The activity of the AS microorganisms was assayed by quantifying the activity of dehydrogenases based on the reduction of 2,3,5-triphenyltetrazolium chloride (TTC) (Avantor, Gliwice, Poland) into red, insoluble 1,2,3-triphenyltetrazolium chloride (TPF) according to Miksch [33].

\subsubsection{Analyzing the Chemical Oxygen Demand}

In order to evaluate the concentration of organic substances in the wastewater, chemical oxygen demand (COD) was measured every 7 days before medium exchange according to the APHA [24].

\subsubsection{Enumerating the Total Heterotrophic Bacteria}

The THB were extracted from the AS flocs by homogenization $(10 s$ at $11,000 \times g)$ and enumerated on the lysogeny broth (LB, BTL, Poland) plates solidified with agar (BTL, Poland) and incubated for $24-72 \mathrm{~h}$ at $23{ }^{\circ} \mathrm{C}$. THB was expressed as $\mathrm{CFU} \mathrm{mL} \mathrm{m}^{-1}$.

\subsubsection{Metabolic Activity of the AS Measuring by BIOLOG}

The functional capacity of the AS microorganisms from different assays during the experimental period was examined using the Biolog system with 96-well EcoPlates ${ }^{\mathrm{TM}}$ and Biolog microstation (BIOLOG Inc., Hayward, CA, USA). At the beginning of the experiment $\left(\mathrm{t}_{0}\right)$ and after 30 days of treatment $\left(t_{30}\right), 10 \mathrm{~mL}$ samples from the bioaugmented assays and respective controls were mixed with $90 \mathrm{~mL}$ of the sterile saline solution and shaken for $1 \mathrm{~h}$ at $130 \mathrm{rpm}$. Afterward, $120 \mu \mathrm{L}$ of the prepared suspensions were used to inoculate each well of the plates and incubated at $22 \pm 1{ }^{\circ} \mathrm{C}$ in the dark for 5 days. The measurements of the absorbance in each well was performed at $590 \mathrm{~nm}$ at the beginning of the experiment and every $12 \mathrm{~h}$. The final results were obtained when the value curve plateau of the average well color development (AWCD) or inflection point was reached (Microlog 4.01 software). The non-linear model described by the Verhulst equation with the four-parameter logistic function was used to calculate the specific rate of the increase in the microbial activity $A(t)[16]$ :

$$
\mathrm{A}(\mathrm{t})=\frac{\mathrm{A}_{\max }}{\left(1+b \cdot \exp ^{\left(-k \cdot t_{50}\right)}\right)}
$$

where $\mathrm{A}_{\max }$ indicates the maximum microbial activity; $\mathrm{t}_{50}$ indicates the time at which the microbial activity has reached half of its maximum, $k$ relates to the steepness slope of $\mathrm{A}(\mathrm{t})$-a function of time for the utilization of each carbon source in the EcoPlate ${ }^{\mathrm{TM}}$ at $\mathrm{t}=\mathrm{t}_{50}$; and $b$-the relative microbial activity increase in an arbitrary constant.

The $\mathrm{Avt}_{50}$ parameter which indicated that the total microbial activity increased at the fastest rate was calculated from the equation:

$$
\operatorname{Avt}_{50}=\frac{\sum_{\mathrm{i}=1}^{\mathrm{n}}(\ln b / k)}{\mathrm{N}}
$$


The calculated parameter was used to compare the control and bioaugmented assays by estimating the functional capacity indices, i.e., average well color development (AWCD), metabolic richness index (S), Gini coefficient (G), Shannon-Weaver diversity index ( $\left.\mathrm{H}_{\mathrm{ECO}}^{\prime}\right)$, and evenness (E). The carbon sources utilized in the EcoPlates ${ }^{\mathrm{TM}}$ were divided into seven groups: polymers, surfactants, phenolic acids, carboxylic acids, amines, amino acids, and carbohydrates [34].

\subsection{Measuring the Protein Concentration}

In order to estimate indirectly the biomass abundance in the AS, the protein concentration was estimated by the Bradford method [32] with bovine serum albumin as a control.

\subsection{Multi-Locus Sequence Typing and Phylogenetic Analysis of the Newly Isolated Strains}

Bacterial DNA was isolated from the pure cultures using the DNA commercial kit (GeneMatrix Bacterial and Yeast Genomic DNA, Eurx, Gdańsk, Poland). The initial molecular identification of analyzed strains was performed by phylogenetic analysis based on the partial sequence of $16 \mathrm{~S}$ rRNA according to the protocol described by Marchlewicz et al. [29]. The nearest taxonomic group was identified by the online tool BLASTN using DDBJ/EMBL/GenBank nucleotide sequence databases. The $16 \mathrm{~S}$ rRNA gene sequences have been stored in the GenBank database (NCBI) under the following accession numbers: MT180428 and MT180429, for AS4 and AS7 strains, respectively. To provide more detailed phylogenetic characteristics, sequencing of the partial sequences of two housekeeping genes, $r p o B$ and $p y r G$ was performed [35]. The sequences of the examined genes were extracted from fully sequenced representative genomes from the genera indicated in the 16S rRNA analysis (Klebsiella, Serratia, and Enterobacter) in the PATRIC database [36]. The nucleotide sequences of both genes were aligned separately in Geneious Prime ${ }^{\circledR}$ 2019.2.3 with global alignment on default settings. The specific primers for both genes were designed from identical sites. For amplification of the partial sequence of the rpoB gene primers: rpoB_F: 5' ATGGTTTACTCCTATACCGAGAA 3', rpoB_R: 5' GCATCATGCGGTAGATTTCTAC 3' and for pyrG gene: pyrG_F: 5' GTCGTATCC TCTCTGGGTAAAG 3', pyrG_R: 5' TTAAGCTGAATCGTTTACAAATATAATC 3' were used. Amplification of both genes was carried out with a program consisting of initial denaturation at $94{ }^{\circ} \mathrm{C}$ for $2 \mathrm{~min}, 30$ cycles of denaturation at $94^{\circ} \mathrm{C}$ for $15 \mathrm{~s}$, annealing at $58^{\circ} \mathrm{C}$ for $30 \mathrm{~s}$, extension at $72{ }^{\circ} \mathrm{C}$ for $90 \mathrm{~s}$, and a final elongation step at $72{ }^{\circ} \mathrm{C}$ for 7 min with Pfu DNA Polymerase (Eurx, Gdańsk, Poland). The partial nucleotide sequences of $r p o B$ gene have been deposited in the GenBank database of NCBI under the accession number MT181967 and MT181969, and pyrG gene under the accession number MT181968 and MT181970 for AS4 and AS7 strains, respectively. Sequences for strains were retrieved from the GenBank database and aligned separately for each gene in Geneious Prime and then for each strain $p y r G, r p o B$, and $16 \mathrm{~S}$ rRNA sequences were concatenated. The final alignment was used to build a maximum likelihood (ML) phylogenetic tree in MEGA X version 10.1.5. The ML analysis was performed with Tamura-Nei model with 1000 bootstrap phylogeny tests. The isolated strains will be deposited in the publicly available German Collection of Microorganisms and Cell Cultures (DSMZ).

\subsection{Measuring the Analgesics Concentrations}

The concentration of tested drugs in the bioaugmented and non-bioaugmented assays and their respective controls were determined using Merck Hitachi reversed-phase High-Performance Liquid Chromatography (HPLC) with a column Ascentis Express ${ }^{\circledR} \mathrm{C} 18(100 \times 4.6 \mathrm{~mm})$, operated in an isocratic mode, pre-column Opti-Solv ${ }^{\circledR}$ EXP, and UV/Vis diode array detector. The mobile phase for the particular drugs detection was consisted as follows: acetonitrile: $1 \%$ acetic acid (50:50, v/v) for IBU and NPX, methanol: $1 \%$ acetic acid (95:5, v/v) for APAP and acetonitrile: 1\% acetic acid:methanol (50:30:20, $\mathrm{v} / \mathrm{v} / \mathrm{v}$ ) for DCF. The flow rate of the mobile phase was $1 \mathrm{~mL} \mathrm{~min}^{-1}$. The NSAIDs and APAP in the supernatant were identified and quantified by comparing their HPLC retention times and UV-visible spectra with respective parameters of external standards. The detection wavelength was 230, 240, 260, and $276 \mathrm{~nm}$ for IBU, APAP, NPX, and DCF, respectively. 


\subsection{Identifying the Intermediates Formed During Degradation}

Every 7 days, the analyses of the secondary metabolites in the bioaugmented assays with the NSAIDs and APAP were performed using liquid chromatography coupled with a mass detector (UHPLC/MS/MS) Shimadzu LC/MS-8040 in reverse phase system, using a Luna Omega C18 $1.6 \mu \mathrm{m}$ column, $100 \times 2.1 \mathrm{~mm}$ (Phenomenex) and mobile phases: A- $5 \mathrm{mM}$ aqueous solution of ammonium acetate $\mathrm{pH} 5.8, \mathrm{~B}$-acetonitrile. The mobile phase flow was $0.4 \mathrm{~mL} \mathrm{~min}^{-1}$ and the oven temperature was $30{ }^{\circ} \mathrm{C}$. The following elution program was used: $0-2 \mathrm{~min}-10 \%$ isocratic $\mathrm{B}, 2-9 \mathrm{~min}$ from $10 \%$ to $70 \% \mathrm{~B}, 9-10 \mathrm{~min}$-isocratic $70 \% \mathrm{~B}, 10-10.5 \mathrm{~min}$-from $70 \%$ to $5 \% \mathrm{~B}, 10.5-14 \mathrm{~min}$-isocratic $5 \% \mathrm{~B}$. Mass spectrometer parameters were as follows: nebulizing gas flow $3 \mathrm{~L} \mathrm{~min}^{-1}$, drying gas flow $8 \mathrm{~L} \mathrm{~min}^{-1}$, temperature $250{ }^{\circ} \mathrm{C}$ desolvation line, $400{ }^{\circ} \mathrm{C}$ heating block temperature. The analyses were performed in multiple reaction monitoring (MRM) mode.

\subsection{Statistical Analyses}

All of the data were expressed as the mean value and standard deviation of three biological replicates. Data were analyzed using Microsoft Office Excel 2010 and Statistica ${ }^{\circledR}$ 13.3 PL (TIBCO Software Inc., Palo Alto, CA, USA). In order to determine whether the pharmaceuticals or bioaugmentation influenced the activity or metabolic properties of microorganisms in the AS, the results were evaluated using ANOVA test. The statistical significance $(p<0.05)$ of any differences were analyzed using one-way ANOVA for considering the effect of drugs or bioaugmentation on the functional diversity indices and the usage of carbon substrates and evaluated by a post-hoc test of the means using the lowest significant differences (LSD) test for normally distributed data or multiple comparisons test (MCT) for results, which did not present normal distribution. For the cluster and Spearman's rank correlation analysis, data were first subjected to min-max normalization according to the equation:

$$
N D=\frac{R D_{i}-R D_{\max }}{R D_{\max }-R D_{\min }}
$$

where, $N D$-normalized data (all of the variables were scaled to the range between 0 and 1 ); $R D_{i}$ - the initial raw data; $R D_{\min }$ - the minimal value of each parameter in a data set; and $\mathrm{RD}_{\max }$ - the maximal value of each parameter in a data set. All of the factors that might have an influence on the changes observed between non- and bioaugmented assays were evaluated by PCA analysis based on the correlation matrix.

\section{Results}

\subsection{The Impact of Pharmaceuticals and Bioaugmentation on the AS Quality}

The results of the TPF concentration measurement indicated that the bioaugmented AS1 assay was characterized by a higher overall metabolic activity compared to the non-bioaugmented assay AS2 (Figure 2). In turn, the bioaugmented biotic control AS4 was characterized by the lowest metabolic activity within the tested systems. Considering the weak metabolic activity observed in the AS4, the increase of this parameter for the AS1 resulted probably from the drugs degradation. It was indicated that the high activity of the bacterial consortium in the control AS3 assay was inhibited by the autochthonous microorganisms which was reflected in the lowest microbial activity in the assay AS4. Moreover, the relatively high bacterial activity observed in the control AS3 was probably connected with the high accessibility of nutrients released from the AS flocs.

In the AS1, THB (CFU mL ${ }^{-1}$ ) during the entire experiment was rather constant. Small differences were also observed for the assay AS2. On the other hand, the greatest differentiation was revealed for the AS3 and AS4 treatments, which were simultaneously characterized by the highest THB. It is noteworthy that in the AS5 assay, to which neither consortia nor pharmaceuticals were added, there was no sharp decrease in the number of microorganisms. 
$\operatorname{COD}\left(\mathrm{mg} \mathrm{L}^{-1} \mathrm{O}_{2}\right.$ ) measurements allowed to estimate system's organic load. The lowest values were calculated for the AS1 and AS4 assays, which indicated that the constructed bacterial consortium was characterized by high efficiency in organic substances removal (Figure 3). For the AS1, the most severe decline in the COD values was observed after 7 days of treatment $\left(t_{7}\right)$ and at the end of the experiment $\left(t_{30}\right)$. For the assay AS2 containing the AS and pharmaceuticals, the COD values were rather constant, with a slight drop on day 21 of the experiment $\left(t_{21}\right)$. However, for the AS2 the level of the observed loading was significantly lower (maximum value reached $1672 \mathrm{mg} \mathrm{L}^{-1} \mathrm{O}_{2}$ ) than those observed for the AS5, where the COD values ranged from 4004 at $\mathrm{t}_{0}$ to $6160 \mathrm{mg} \mathrm{L}^{-1} \mathrm{O}_{2}$ at $\mathrm{t}_{30}$, without significant reduction at any sampling time.

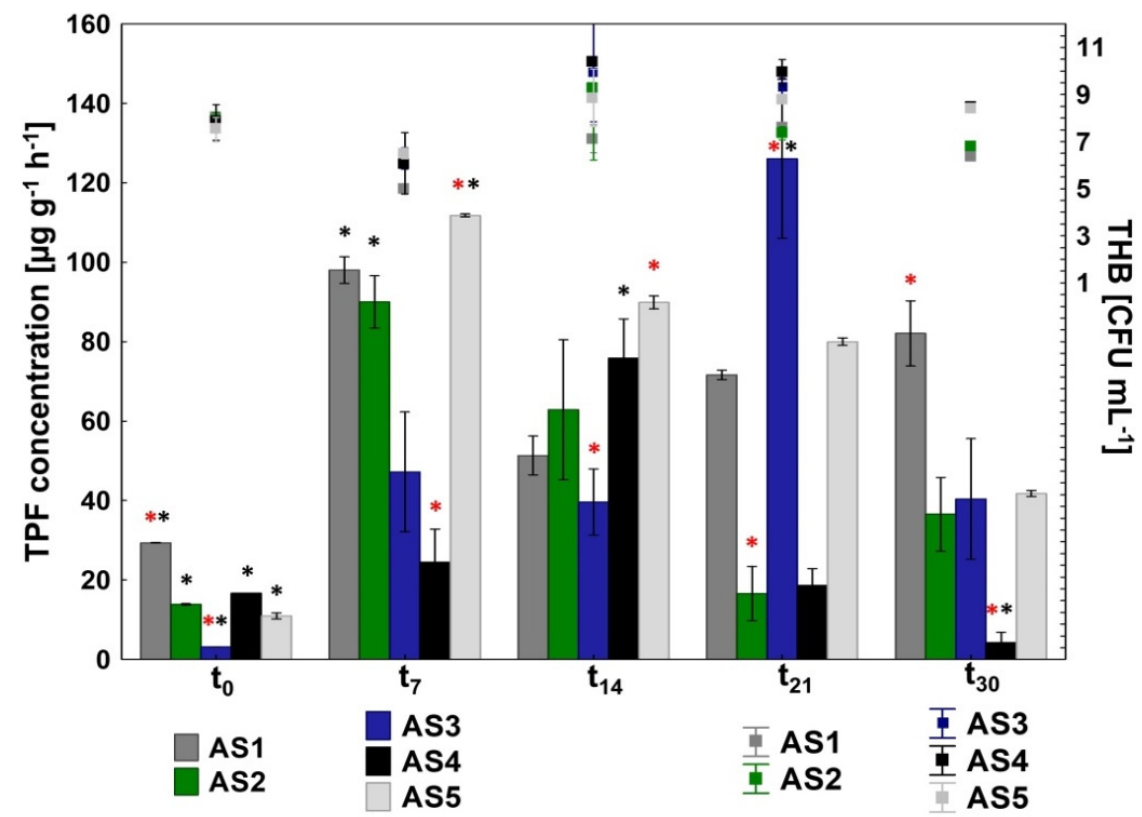

Figure 2. Bacteria consortium evolution weekly assessed by dehydrogenases activity (TPF, $\mu \mathrm{g} \mathrm{g}^{-1} \mathrm{~h}^{-1}$ )—bars, and THB enumeration ( $\log \mathrm{CFU} \mathrm{mL}{ }^{-1}$ )—points, on the experimental conditions (assays AS1-AS5), during the experimental period (30 days). The data are presented as the mean values of three biological replicates \pm standard deviation. Columns marked with red asterisks are significantly different ( $p<0.05$, multiple comparisons (MCT) test) considering different experimental conditions at the same sampling time, and marked with black asterisks-within each assay considering the sampling day. TPF_-triphenyltetrazolium chloride, THB-Total Heterotrophic Bacteria.

In order to evaluate indirectly the biomass in each experimental condition, the concentration of proteins released from the flocs was measured (Figure 4). The obtained results showed that the highest overall concentration of proteins was measured in the biotic non-bioaugmented control AS5. Considering the periodic feeding of the AS with fresh SW without the addition of bacterial consortium and/or NSAIDs, good quality of the AS in this assay was expected. Indeed, there were no severe disturbances between the AS4 and AS5 assays that indicated no negative influence of inoculated bacterial consortium on the AS condition. The general trends in protein concentrations were similar for all tested systems. Similarly, the successive bioaugmentation was not significantly reflected in the overall protein concentrations, because most of the differences were not statistically significant. 
A

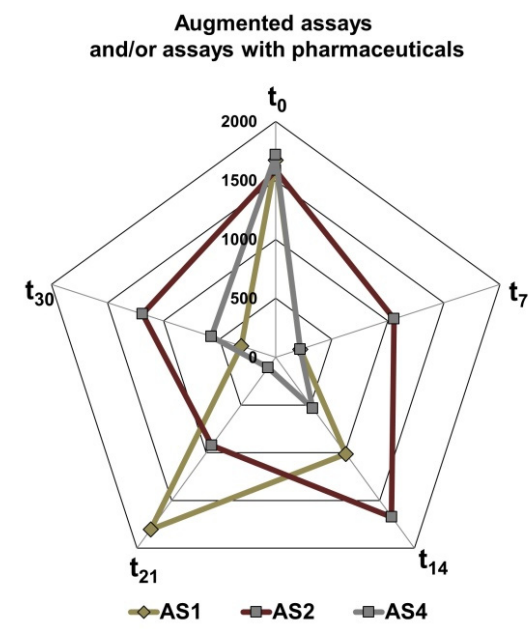

B

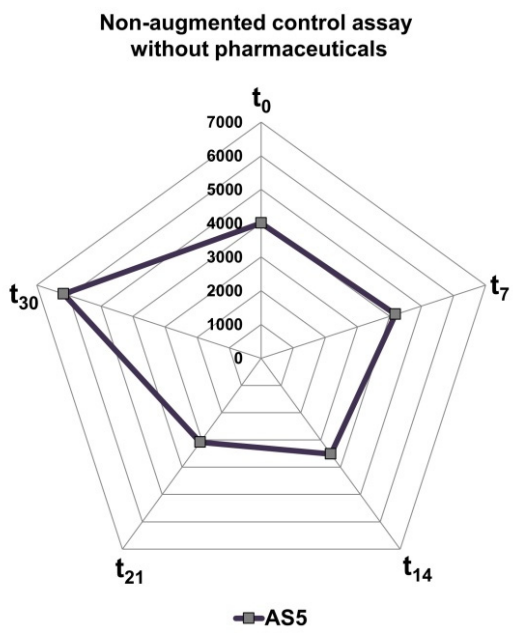

Figure 3. Weekly activated sludge COD $\left(\mathrm{mg} \mathrm{L}^{-1} \mathrm{O}_{2}\right)$ content on the five AS assays during the experimental period: (A) the AS1, AS2, and AS4 are the bioaugmented assays and/or assays with pharmaceuticals; (B) the AS5 assay is the control. COD—carbon oxygen demand.

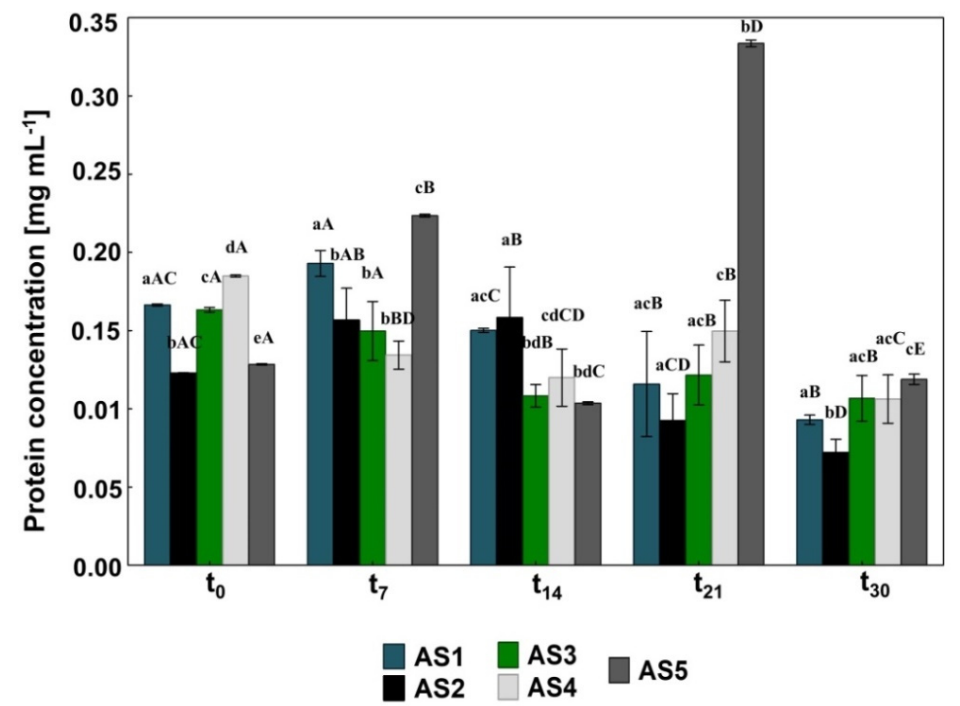

Figure 4. Protein concentrations ( $\mathrm{mg} \mathrm{mL}^{-1}$ ) in the five assays (AS1-AS5) during 30 days of treatment. The data are presented as the mean values of three biological replicates \pm standard deviation. The values of protein concentration with different lower-case letters $(\mathrm{a}, \mathrm{b}, \mathrm{c}, \mathrm{d}, \mathrm{e})$ are significantly different $(p<0.05$, post hoc lowest significant differences (LSD) test) considering different experimental conditions at the same sampling time. The values of protein concentration with different upper-case letters (A, B, C, D, E) are significantly different $(p<0.05$, post hoc LSD test) within each assay considering the sampling day.

\subsection{Microbial Activity in the Activated Sludge}

To compare the metabolic activity and functional capacity of microorganisms in the tested systems, the EcoPlate ${ }^{\mathrm{TM}}$ indices were estimated. It was indicated that the bioaugmentation of the AS caused a slight increase in the microbial diversity at $\mathrm{t}_{0}$ what was observed as a significant difference in $\mathrm{H}^{\prime} \mathrm{Eco}$ values between AS1/ $t_{0}$ and AS2/ $t_{0}$ (Table 3 ). The highest value of this parameter was calculated for AS5 at $t_{30}$. Although the average and maximum microbial activity were the lowest in the non-bioaugmented and not fed AS5 assay, the microbial communities achieved half of their overall maximal activity in the shortest time $\left(\mathrm{Avt}_{50}\right)$ (Table 4). The presence of the pharmaceuticals in the assay AS2 significantly influenced the microorganisms abundance, which was reflected in the higher G coefficient value compared to its value calculated for the control AS5 assay. Neither the bioaugmentation nor the 
NSAIDs and APAP influenced the $S$ index. Microorganisms in all assays were able to utilize $83 \%-89 \%$ of the carbon sources available on the EcoPlate, which was correlated with the $\mathrm{S}$ values in the range from 26 to 28 .

To determine whether the presence of the NSAIDs or APAP and bioaugmentation affected the utilization patterns in the experimental conditions, all EcoPlate substrates were grouped by their chemical guild. It was found that the intensity of carbohydrates usage increased in the AS1 and AS4 by $22 \%$ and $12 \%$ during the experimental period (30 days), respectively. Additionally, in the assay AS1 fed with the pharmaceuticals a significant increase in carboxylic acids usage was also recorded (Figures 5 and 6). The shifts in amino acids and amines utilization, reflecting the changes in nitrogen sources usage, clearly indicated that inoculation of bacterial consortium into the AS1 and AS4 caused a significant decrease in the utilization of nitrogen containing substrates from $30 \%$ to $20 \%$ and $22 \%$ during 30 days of wastewater treatment, respectively. In turn, the presence of the NSAIDs and APAP in the assay AS2 caused a significant increase in phenolic acids utilization from $0.92 \%$ at $t_{0}$ to $6.15 \%$ at $t_{30}$. For microorganisms from the AS1 assay, the most significant difference in the utilization pattern was in putrescine, pyruvic acid methyl ester, glycogen, and L-arginine consumption, which were more intensively metabolized at $t_{0}$ than at $t_{30}$. Contrary, under the same conditions they used less D-cellobiose, D-mannitol, and D-lactose. In comparison, the microorganisms in the non-bioaugmented AS2 intensively metabolized at $t_{0}$ carbon sources including e.g., glycogen, D-mannitol, Tween 40, N-acetyl-D-glucosamine, or D-galactouronic acid. However, during the following days of the experiment, the ability of microorganisms to utilize pyruvic acid methyl ester, D-asparagine, L-serine, putrescine, and D-malic acid increased.



Figure 5. Usage of carbon substrate guilds by the microorganisms from different experimental conditions (assays AS1, AS2, AS4, and AS5) during the experimental period (30 days). The different letters $(a, b, c, d, e)$ indicate significant differences $(p<0.05$, LSD test) in the usage of substrates guilds considering different experimental conditions and/or sampling day.

Table 3. The functional diversity indices for the AS in different experimental conditions.

\begin{tabular}{|c|c|c|c|c|c|c|}
\hline Parameter & AS1/t $t_{0}$ & AS2/t $\mathbf{t}_{0}$ & $\mathrm{AS} 1 / \mathbf{t}_{30}$ & $\mathrm{AS} 2 / \mathrm{t}_{30}$ & $\mathrm{AS} 4 / \mathrm{t}_{30}$ & AS $5 / t_{30}$ \\
\hline \multicolumn{7}{|c|}{ Functional Diversity Indices } \\
\hline $\mathrm{H}_{\text {Eco }}^{\prime}$ & $1.27 \pm 0.02^{\mathrm{a}}$ & $1.24 \pm 0.02^{b}$ & $1.28 \pm 0.02^{\mathrm{a}}$ & $1.28 \pm 0.01^{\mathrm{a}}$ & $1.29 \pm 0.01^{\mathrm{c}}$ & $1.31 \pm 0.02^{\mathrm{d}}$ \\
\hline AWCD & $1.26 \pm 0.04^{\mathrm{a}}$ & $1.12 \pm 0.11^{b}$ & $0.99 \pm 0.09^{c}$ & $0.94 \pm 0.05^{c}$ & $0.92 \pm 0.07^{c}$ & $0.78 \pm 0.04^{\mathrm{d}}$ \\
\hline G & $0.55 \pm 0.04^{\mathrm{a}}$ & $0.68 \pm 0.05^{b}$ & $0.62 \pm 0.03^{c}$ & $0.59 \pm 0.03^{c}$ & $0.54 \pm 0.03$ ad & $0.51 \pm 0.04^{\mathrm{d}}$ \\
\hline$S$ & $27.11 \pm 3.10^{\mathrm{a}}$ & $22.00 \pm 1.23^{b}$ & $25.89 \pm 1.90^{\mathrm{a}}$ & $26.56 \pm 0.88^{\mathrm{a}}$ & $27.67 \pm 1.22^{\mathrm{a}}$ & $26.22 \pm 3.07^{a}$ \\
\hline E & $0.88 \pm 0.02^{\mathrm{a}}$ & $0.92 \pm 0.02 b c$ & $0.90 \pm 0.01 \mathrm{ac}$ & $0.90 \pm 0.01^{\mathrm{a}}$ & $0.90 \pm 0.01^{\mathrm{a}}$ & $0.93 \pm 0.03^{b}$ \\
\hline
\end{tabular}

$\mathrm{H}^{\prime}$ Eco-Shannon-Weaver diversity index; AWCD-average well color development; G-Gini coefficient; $\mathrm{S}$-metabolic richness index; E-evenness. In each row the means with different letters $(\mathrm{a}, \mathrm{b}, \mathrm{c}, \mathrm{d})$ are significantly different $(p<0.05$, LSD test) considering different experimental conditions and/or sampling day. 
Table 4. The kinetic parameters for the AS in different experimental conditions.

\begin{tabular}{|c|c|c|c|c|c|c|}
\hline Parameter & $\mathbf{A S 1} 1 / \mathrm{t}_{0}$ & AS2/t $t_{0}$ & AS1/ $\mathbf{t}_{30}$ & $\mathrm{AS} 2 / \mathrm{t}_{30}$ & AS $4 / t_{30}$ & AS5/ $\mathbf{t}_{30}$ \\
\hline \multicolumn{7}{|c|}{ Kinetic Parameters } \\
\hline $\mathrm{A}_{\max }$ & $1.29 \pm 0.04^{\mathrm{ac}}$ & $1.04 \pm 0.13^{b}$ & $1.32 \pm 0.09^{a}$ & $1.19 \pm 0.05^{\mathrm{ab}}$ & $1.25 \pm 0.10^{\mathrm{ac}}$ & $1.10 \pm 0.06^{b c}$ \\
\hline$b$ & $50.07 \pm 5.63^{a}$ & $129.88 \pm 19.04^{b}$ & $221.59 \pm 34.59^{\mathrm{cd}}$ & $180.78 \pm 19.50^{b c}$ & $227.67 \pm 30.22^{d}$ & $674.21 \pm 60.82^{e}$ \\
\hline$k$ & $0.069 \pm 0.004^{a}$ & $0.082 \pm 0.006^{b}$ & $0.098 \pm 0.003^{c}$ & $0.100 \pm 0.004^{c}$ & $0.090 \pm 0.002^{\mathrm{d}}$ & $0.148 \pm 0.005^{\mathrm{e}}$ \\
\hline $\mathrm{Avt}_{50}$ & $57.15 \pm 2.91 \mathrm{ac}$ & $58.054 \pm 1.70 \mathrm{ad}$ & $54.78 \pm 1.18^{b c}$ & $52.65 \pm 1.17^{b}$ & $60.46 \pm 1.46^{\mathrm{d}}$ & $44.62 \pm 1.19^{\mathrm{e}}$ \\
\hline
\end{tabular}

Amax-maximum microbial activity; $b$ - the relative microbial activity increase in an arbitrary constant; $k$-the specific rate of activity increase; Avt50 - time at which the total microbial activity increased at the fastest rate. In each row the means with different letters $(\mathrm{a}, \mathrm{b}, \mathrm{c}, \mathrm{d}, \mathrm{e})$ are significantly different $(p<0.05$, LSD test) considering different experimental conditions and/or sampling day.

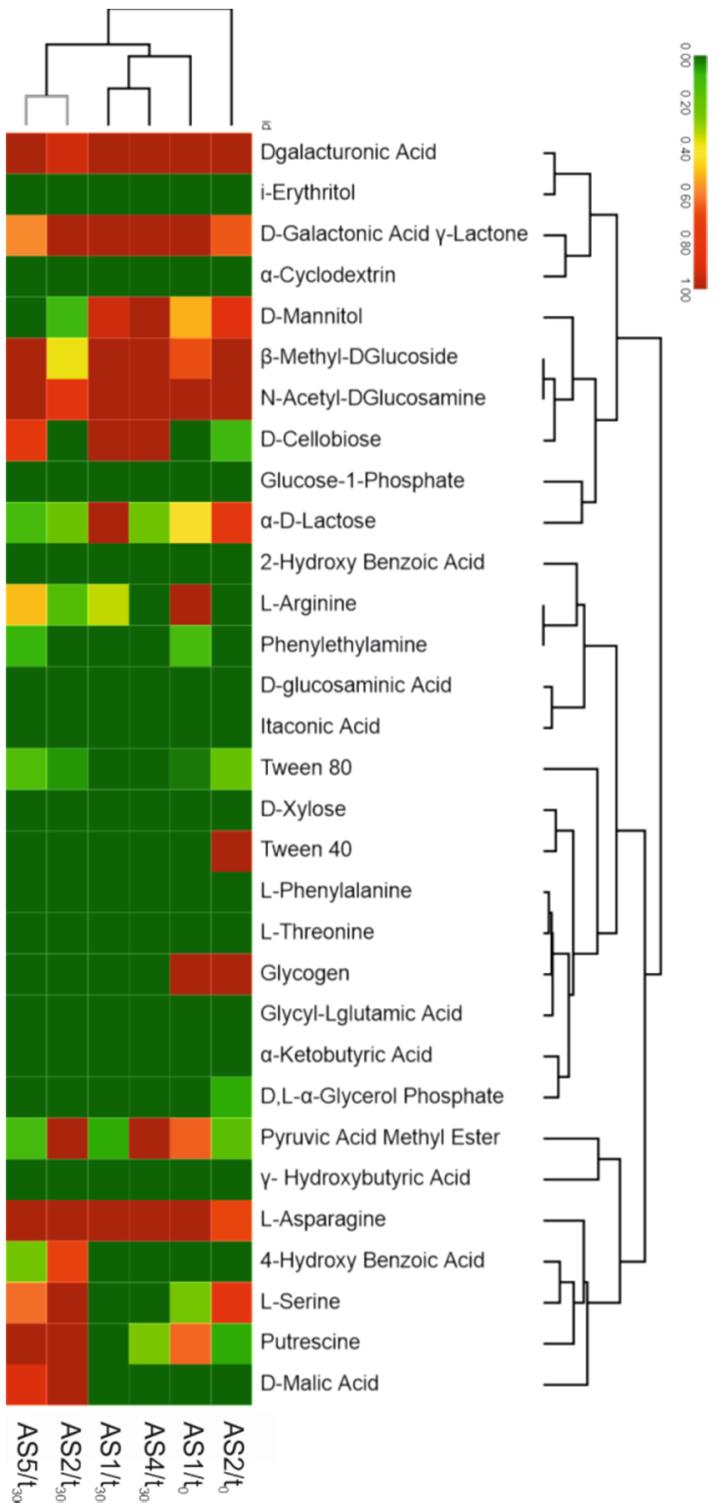

Figure 6. Cluster analysis based on the Spearman's rank correlation coefficients estimated for the Biolog ${ }^{\circledR}$ EcoPlates ${ }^{\mathrm{TM}}$ carbon sources utilization patterns for the different experimental conditions (assays AS1, AS2, AS4, and AS5) during the experimental period (30 days). All data were normalized and presented as a color scale ranging from green (MIN, means 0 ) to red (MAX, means 1 ).

\subsection{Removal of Pharmaceuticals}

As the obtained results showed, the degraded doses of APAP, IBU, and NPX were quite similar in the bioaugmented AS1 and the non-bioaugmented AS2 assays (Table 5). 
Table 5. Degraded doses of analyzed pharmaceuticals in the AS1, AS2, and AS3 assays during 30 days of treatment.

\begin{tabular}{|c|c|c|c|}
\hline Pharmaceutical & Time of Analysis & Assay & Degraded Dose $\left(\mathrm{mg} \mathrm{L}^{-1}\right)$ \\
\hline \multirow{12}{*}{ APAP } & \multirow{3}{*}{$t_{7}$} & AS1 & 1.0 \\
\hline & & AS2 & 1.0 \\
\hline & & AS3 & 1.0 \\
\hline & \multirow{3}{*}{$t_{14}$} & AS1 & 1.0 \\
\hline & & AS2 & 1.0 \\
\hline & & AS3 & 1.0 \\
\hline & \multirow{3}{*}{$t_{21}$} & AS1 & 1.0 \\
\hline & & AS2 & 1.0 \\
\hline & & AS3 & 1.0 \\
\hline & \multirow{3}{*}{$t_{30}$} & AS1 & 1.0 \\
\hline & & AS2 & 1.0 \\
\hline & & AS3 & 1.0 \\
\hline \multirow{12}{*}{ IBU } & \multirow{3}{*}{$t_{7}$} & AS1 & 1.0 \\
\hline & & AS2 & 1.0 \\
\hline & & AS3 & 1.0 \\
\hline & \multirow{3}{*}{$\mathrm{t}_{14}$} & AS1 & 1.0 \\
\hline & & AS2 & 1.0 \\
\hline & & AS3 & 1.0 \\
\hline & \multirow{3}{*}{$t_{21}$} & AS1 & 1.0 \\
\hline & & AS2 & 1.0 \\
\hline & & AS3 & 1.0 \\
\hline & \multirow{3}{*}{$t_{30}$} & AS1 & 1.0 \\
\hline & & AS2 & 1.0 \\
\hline & & AS3 & $0.94 \pm 0.02$ \\
\hline \multirow{12}{*}{ NPX } & \multirow{3}{*}{$t_{7}$} & AS1 & 0.5 \\
\hline & & AS2 & 0.5 \\
\hline & & AS3 & 0.5 \\
\hline & \multirow{3}{*}{$t_{14}$} & AS1 & 0.5 \\
\hline & & AS2 & 0.5 \\
\hline & & AS3 & 0.5 \\
\hline & \multirow{3}{*}{$t_{21}$} & AS1 & 0.5 \\
\hline & & AS2 & 0.5 \\
\hline & & AS3 & 0.5 \\
\hline & \multirow{3}{*}{$t_{30}$} & AS1 & $0.34 \pm 0.00$ \\
\hline & & AS2 & $0.32 \pm 0.05$ \\
\hline & & AS3 & $0.44 \pm 0.01$ \\
\hline \multirow{12}{*}{ DCF } & \multirow{3}{*}{$t_{7}$} & AS1 & $0.14 \pm 0.08$ \\
\hline & & AS2 & $0.12 \pm 0.04$ \\
\hline & & AS3 & $0.33 \pm 0.04$ \\
\hline & \multirow{3}{*}{$\mathrm{t}_{14}$} & AS1 & $0.5 \pm 0.00$ \\
\hline & & AS2 & $0.34 \pm 0.04$ \\
\hline & & AS3 & $0.39 \pm 0.02$ \\
\hline & \multirow{3}{*}{$t_{21}$} & AS1 & $0.46 \pm 0.01$ \\
\hline & & AS2 & $0.31 \pm 0.02$ \\
\hline & & AS3 & 0.5 \\
\hline & \multirow{3}{*}{$t_{30}$} & AS1 & $0.49 \pm 0.00$ \\
\hline & & AS2 & $0.43 \pm 0.05$ \\
\hline & & AS3 & $0.48 \pm 0.01$ \\
\hline
\end{tabular}

The data are presented as the mean values of three biological replicates \pm standard deviation. The last period is longer than the previous due to the measurements in the last day of the experiment ( 30 day). 
Over the experiment, the AS microorganisms in the AS1, AS2, and AS3 assays completely utilized four doses of APAP and IBU. Degradation of NPX proceeded similarly in the AS1 and AS2 treatment with NPX residue at $0.16 \pm 0.00-0.18 \pm 0.05 \mathrm{mg} \mathrm{L}^{-1}$. More visible changes were observed in DCF degradation, which was the most ineffective in the AS2 assays with the autochthonous microorganisms. The residue of DCF in the AS2 at $\mathrm{t}_{7}$ was $0.38 \pm 0.04 \mathrm{mg} \mathrm{L}^{-1}$, at $\mathrm{t}_{14}-0.16 \pm 0.04 \mathrm{mg} \mathrm{L}^{-1}$, at $t_{21}-0.19 \pm 0.02 \mathrm{mg} \mathrm{L}^{-1}$ and at $\mathrm{t}_{30}-0.07 \pm 0.05 \mathrm{mg} \mathrm{L}^{-1}$. The presence of the bacterial consortium in the AS1 significantly enhanced DCF degradation compared to its removal by microorganisms in the AS2, with DCF residue at $\mathrm{t}_{7}-0.36 \pm 0.08 \mathrm{mg} \mathrm{L}^{-1}$, at $\mathrm{t}_{14}-0.00 \pm 0.00 \mathrm{mg} \mathrm{L}^{-1}$, at $\mathrm{t}_{21}-0.04 \pm 0.01 \mathrm{mg} \mathrm{L}^{-1}$, and at $t_{30}-0.01 \pm 0.00 \mathrm{mg} \mathrm{L}^{-1}$. Simultaneously, the incomplete degradation of pharmaceuticals in the AS3 assay with the sterilized AS and bacterial consortium indicated that the degradation of drugs in the AS1 treatment was partly enhanced by the indigenous microorganisms. The final concentration of IBU in the AS3 was $0.05 \pm 0.02 \mathrm{mg} \mathrm{L}^{-1}, \mathrm{NPX}-0.06 \pm 0.01 \mathrm{mg} \mathrm{L}^{-1}$, and DCF-0.02 $\pm 0.01 \mathrm{mg} \mathrm{L}^{-1}$, whereas, APAP was not detected.

\subsection{Secondary Metabolites Formation}

In order to identify the most important secondary metabolites formed during the degradation of the analyzed drugs, the AS from the assay AS1 was subjected to analysis using the UHPLC MS/MS. The transition of $\mathrm{m} / \mathrm{z}$ of the precursors to the $\mathrm{m} / \mathrm{z}$ of the products is given in Table S1. By-products identified after every 7 days of treatment are summarized in Table 6. Among the identified metabolites, 2-OH-IBU and 4-OH-DCF were characterized by the highest concentration.

Table 6. Secondary metabolites identified in the AS1 assay during 30 days of treatment.

\begin{tabular}{|c|c|c|c|c|}
\hline Pharmaceutical & Metabolite & Time of Analysis & RT & UHPLC MS/MS (ng mL ${ }^{-1}$ ) \\
\hline \multirow{8}{*}{ APAP } & 4-aminophenol & $t_{7}$ & 1.93 & $<40.0$ \\
\hline & \multirow{7}{*}{ Hydroquinone } & $\mathrm{t}_{14}$ & & $<40.0$ \\
\hline & & $t_{21}$ & & $<40.0$ \\
\hline & & $t_{30}$ & & $<40.0$ \\
\hline & & $t_{7}$ & nd & nd \\
\hline & & $\mathrm{t}_{14}$ & & nd \\
\hline & & $t_{21}$ & & nd \\
\hline & & $t_{30}$ & & nd \\
\hline \multirow{4}{*}{ NPX } & \multirow{4}{*}{ O-desmethyl-NPX } & $t_{7}$ & \multirow{4}{*}{4.89} & $<20.0$ \\
\hline & & $\mathrm{t}_{14}$ & & $<20.0$ \\
\hline & & $t_{21}$ & & $<20.0$ \\
\hline & & $t_{30}$ & & $<20.0$ \\
\hline \multirow{8}{*}{ IBU } & \multirow[t]{4}{*}{ 1-OH-IBU } & $t_{7}$ & \multirow[t]{4}{*}{5.25} & $<5.0$ \\
\hline & & $t_{14}$ & & $<5.0$ \\
\hline & & $t_{21}$ & & $<5.0$ \\
\hline & & $t_{30}$ & & $<5.0$ \\
\hline & \multirow[t]{4}{*}{ 2-OH-IBU } & $t_{7}$ & \multirow[t]{4}{*}{4.81} & $<5.0$ \\
\hline & & $t_{14}$ & & $<5.0$ \\
\hline & & $t_{21}$ & & $8.6 \pm 0.1$ \\
\hline & & $t_{30}$ & & $<5.0$ \\
\hline \multirow{8}{*}{ DCF } & \multirow[t]{4}{*}{ DCF lactam } & $t_{7}$ & \multirow[t]{4}{*}{8.98} & $<20.0$ \\
\hline & & $\mathrm{t}_{14}$ & & $<20.0$ \\
\hline & & $t_{21}$ & & $<20.0$ \\
\hline & & $t_{30}$ & & $<20.0$ \\
\hline & \multirow[t]{4}{*}{ 4-OH-DCF } & $t_{7}$ & \multirow{4}{*}{6.11} & $48.9 \pm 0.7$ \\
\hline & & $t_{14}$ & & $72.1 \pm 2.2$ \\
\hline & & $t_{21}$ & & $45.9 \pm 3.4$ \\
\hline & & $t_{30}$ & & $<20.0$ \\
\hline
\end{tabular}

The data are presented as the mean values of three biological replicates \pm standard deviation. The last period is longer than the previous due to the measurements in the last day of the experiment ( 30 day). RT-retention time (min); nd-not detected. 


\subsection{New Diclofenac-Degrading Strains}

To impose a strong selection pressure, the higher concentrations of DCF than those detected in the WWTPs effluents were used to isolate two new DCF-degrading bacterial strains. The phylogenetic analysis of the isolates was performed based on the partial sequences of $16 \mathrm{~S}$ rRNA, and two housekeeping genes, $p y r G$ and $r p o B$ according to literature data [35]. Newly isolated strains were assigned as Serratia proteamaculans AS4 and Rahnella bruchi AS7 (Figure 7). It is worth emphasizing that this is the first report about Serratia and Rahnella able to degrade DCF. Both strains are rod-shaped Gram-negative bacteria with creamy, smooth, and glossy colonies. The abilities of both strains to degrade DCF were studied under the co-metabolic conditions with glucose, because none of them were capable of utilizing DCF as a sole carbon and energy source. It was found that under such conditions S. proteamaculans AS4 and R. bruchi AS7 were able to degrade DCF at the concentrations of 0.479 and $0.540 \mathrm{mg} \mathrm{L}^{-1}$ within 14 days, respectively (Figure 8).

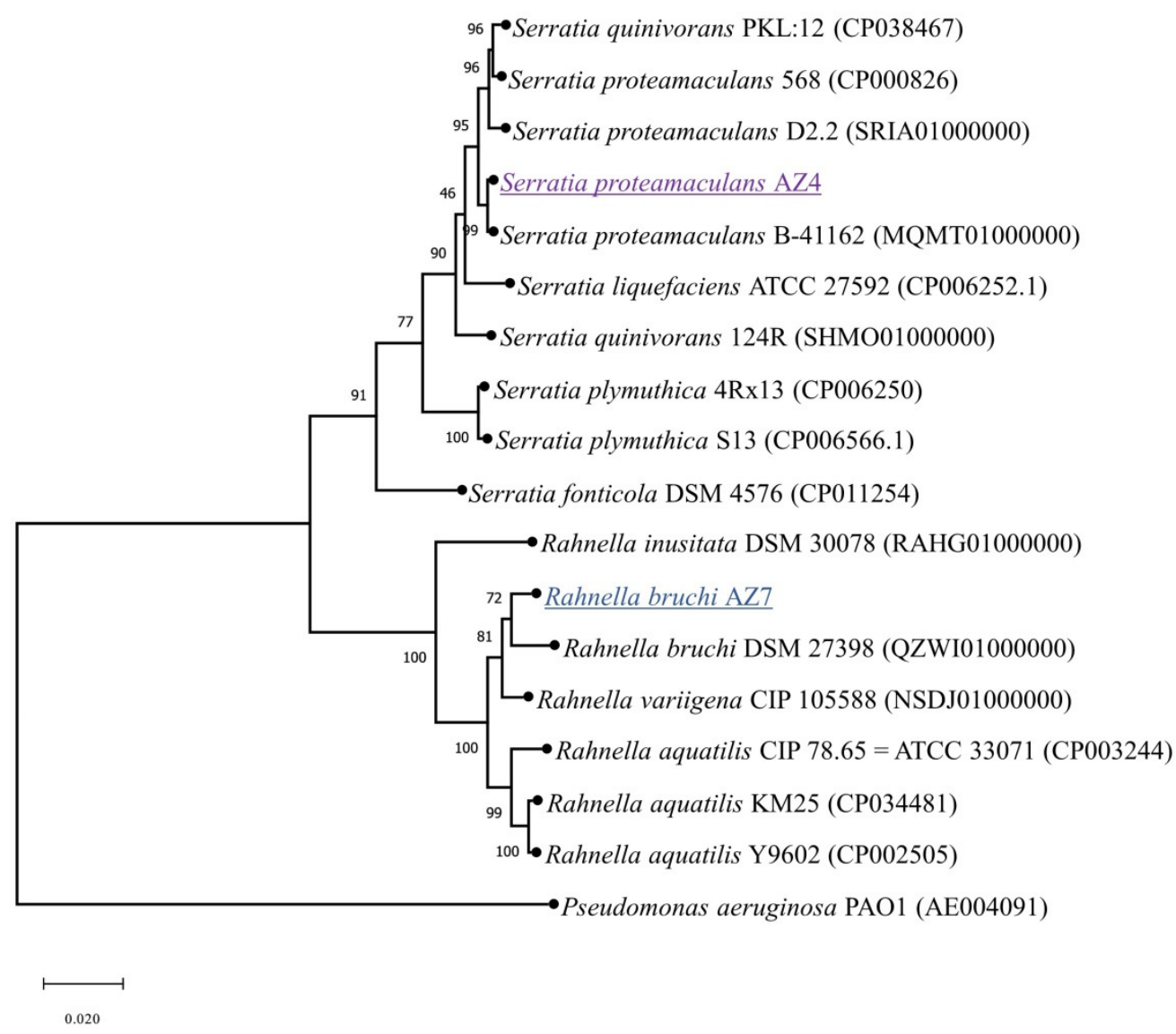

Figure 7. Phylogenetic tree of the newly isolated strains Serratia proteamaculans AS4 and Rahnella bruchi AS7 based on the partial sequences of $16 \mathrm{~S}$ rDNA, and two housekeeping genes: CTP synthase (pyrG) and subunit beta of RNA polymerase $(r p o B)$. Branching percentage values were determined with the use of 1000 bootstraps phylogeny test. The accession number for genomes are shown in brackets. The tree was constructed using the maximum likelihood method. The scale bar represents $1 \%$ nucleotide sequence divergence. 


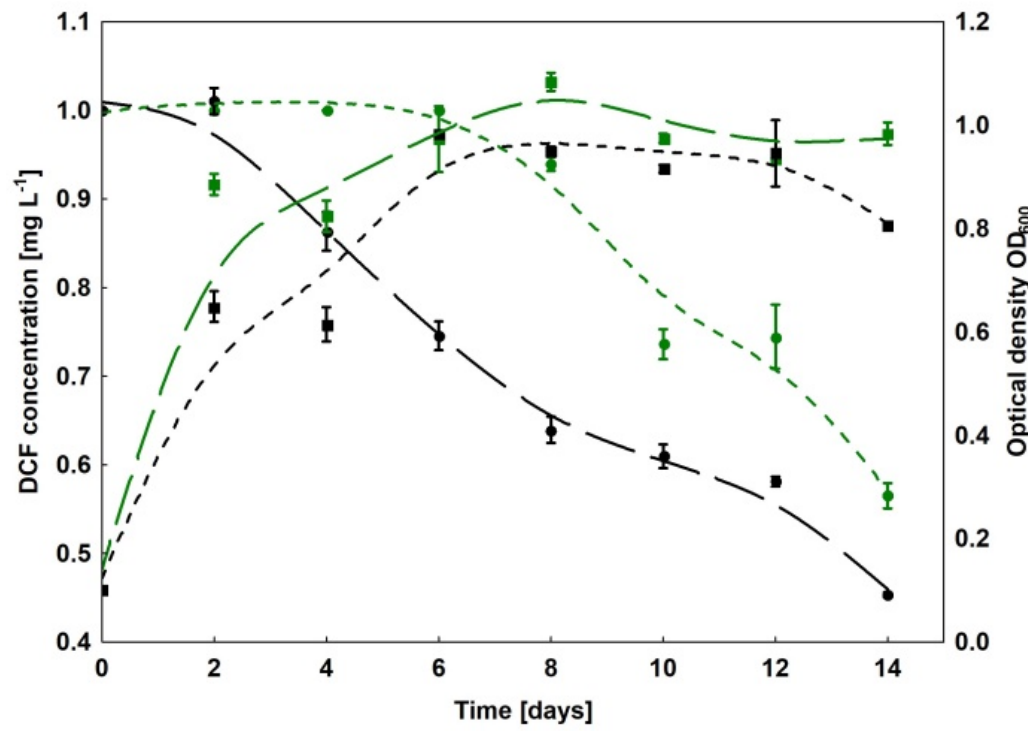

DCF strain AS4

T. $\mathrm{OD}_{600}$ strain AS4

DCF strain AS7

I. $\mathrm{OD}_{600}$ strain AS7

Figure 8. Changes in the optical density $\left(\mathrm{OD}_{600}\right)$ and degradation of DCF by S. proteamaculans AS4 and R. bruchi AS7 under co-metabolic conditions with glucose $\left(1 \mathrm{~g} \mathrm{~L}^{-1}\right)$. The data are presented as the mean values of three biological replicates \pm standard deviation.

\section{Discussion}

\subsection{The Impact of Bioaugmentation and Pharmaceuticals on the AS Quality and Metabolic Diversity}

Due to the incomplete removal and poor biodegradability, the NSAIDs and other analgesics are among the most frequently detected organic contaminants in different natural matrices. Moreover, the lack of sustainable approaches for the removal of the NSAIDs contributes to their continuous release to the environment in the parent forms or as active or more stable metabolites [37]. This can lead to their accumulation in trophic chains and cause long-term adverse effects in living organisms [38]. For pharmaceuticals removal, the AS technology frequently followed by additional physicochemical methods is widely used in various European Union countries [39]. It is worth emphasizing that biodegradation is the dominant mechanism for the removal of acidic drugs, i.e., IBU, NPX, and DCF, while sorption and volatilization appear to be of secondary importance $[40,41]$. This is especially important for DCF, the most toxic NSAID among those chosen for analysis, due to its weak adsorption on suspended solids, which results from the occurrence of DCF molecule in the form of an ion at neutral $\mathrm{pH}$ [42]. However, it is worth noting that in the literature, some contradictory results about the sorption of the NSAIDs to the AS flocs were published-some authors reported that sorption is relevant for hydrophobic compounds e.g., the poly-cyclic NSAIDs [41]. Despite that, in most published papers related to sorption of the NSAIDs, the authors highlighted that these mechanisms are negligible [42].

Although bioaugmentation has proven to be a valuable strategy to improve the operational parameters of the biological wastewater treatment systems and enhance the removal of various pollutants, there is scarce information about its application for the treatment of wastewater containing the prevalent pharmaceuticals [43]. In this study, we focused mainly on the metabolic response and biochemical diversity alterations in the AS during feeding with low concentrations of the drugs. As Almeida et al. [44] reported, biodegradation is rarely studied in terms of the mixture of NSAIDs and analgesics, where synergistic effects of the presence of one drug on another are widely observed. It is well known that a combination of different compounds can affect biodegradation due to its inhibition or by competition and toxicity $[44,45]$.

In the present study, the multidirectional effects of the mixture of four popular analgesics present in wastewater at low concentrations as well as the successive bioaugmentation of the AS with pharmaceuticals-degrading strains on the AS quality were studied. The bioaugmentation of the AS with the designed microbial consortium was intended to enhance the removal efficiency of selected 
analgesics. It is generally considered as a safe method of bioremediation if it does not disturb the balance of the ecosystem into which allochthonous microorganisms are introduced. The indicator of this equilibrium may be the metabolic activity and diversity of the entire microbiome. Simultaneously, the metabolic activity of the AS microbial communities is the crucial indicator of the effectiveness of biological wastewater treatment [46]. So far, the functional capacity of the AS microorganisms that have been exposed to the NSAIDs and APAP is not well documented or discussed in the literature. Herein, the inoculation of the AS1 assay with the bacterial consortium caused a slight increase in the metabolic activity and metabolic richness compared to the non-bioaugmented assay AS2. It might indicate that the composition and number of introduced microorganisms were correctly estimated-on the one hand, the selected consortium did not dominate in the AS, on the other hand its addition positively correlated with the increase in the functional diversity in this ecosystem. Therefore, it could be suggested that there was no competition for the carbon sources and incompatibility between the inoculated consortium and autochthonous microorganisms. If the number of introduced microorganisms is too high, a decrease in the $\mathrm{H}^{\prime}$ ECO value can be expected. Such a relationship was reported by Hailei et al. [47] through the metagenomic sequencing of the bioaugmented AS treated with coking wastewater. Similarly, the inoculation of the AS with Phanerochaete chrysosporium increased bacterial and eukaryotic richness but reduced their diversity. The increase in the metabolic richness index in the bioaugmented AS in the initial phase of the experiment was also observed in this study and it was connected with more intense metabolism of such substrates as putrescine, pyruvic acid methyl ester, L-asparagine, and L-arginine. This could suggest that the introduction of bacterial consortium permitted the utilization of a wider group of substrates by microbial communities compared to the non-bioaugmented AS. The utilization patterns of seven selected biochemical guilds were found to vary in the particular AS assays during 30 days of treatment. It can be suggested that no further changes in the $S$ values observed for the AS assays after that period could be a result of metabolic specialization of the AS microorganisms caused by the presence of allochthonous bacterial strains and/or analgesics as additional carbon sources. The autochthonous AS microorganisms increased utilization of phenolic compounds and those containing nitrogen, while carboxylic acids and carbohydrates were metabolized more intensively in the bioaugmented AS. The intensification of metabolism of phenolic compounds and those containing nitrogen by the AS microorganisms as the microbial response to the presence of harmful leachate from the Kalina pond (Świętochłowice, Poland) in wastewater was also observed by Michalska et al. [16]. The authors assumed that the presence of the leachate in wastewater caused the metabolic specialization of the AS microorganisms with the simultaneous loss of the functionally significant microorganisms. In this study, such drastic shifts were not observed-the activity and functional diversity of the AS microorganisms did not decrease after exposure to low concentrations of analgesics and/or the inoculation of the bacterial consortium. Moreover, the biomass and THB remained also rather constant. This might indicate that applied treatments did not disturb the balance of the AS microbial communities under fluctuating conditions in this ecosystem. Additionally, the overall metabolic activity expressed as the activity of dehydrogenases in the bioaugmented AS exposed to the analgesics (assay AS1) was higher compared to the non-bioaugmented AS (assay AS2 on days 21 and 30 of the experiment). It could suggest that the bacterial consortium stimulated the metabolic activity of the AS microorganisms in the long-term presence of the NSAIDs and APAP as the additional carbon sources. In comparison, the absence of the analgesics in the bioaugmented AS (assay AS4) caused the decrease in the activity of autochthonous microbial communities on days 21 and 30 of the experiment, what indicated that the additional carbon sources affected the metabolism of the AS microorganisms. Simultaneously, a rather constant total count of heterotrophic bacteria in the AS1 and AS2 assays suggested that the exposure of microorganisms to the NSAIDs and APAP did not eliminate drastically microbial species from the AS. Similarly, Hu et al. [48] observed that the microorganisms originated from the AS were well acclimated and degraded a low initial concentration of plasticizer di- $n$-butyl phthalate $\left(10 \mathrm{mg} \mathrm{L}^{-1}\right)$, while at a higher concentration $\left(100 \mathrm{mg} \mathrm{L}^{-1}\right)$ they poorly removed it. 
The solution was the bioaugmentation of the AS with Micrococcus sp. which enhanced the removal efficiency of higher concentration of the target compound.

\subsection{Pharmaceuticals Removal and Secondary Metabolites Formation}

In this study, we focused on the visualization and proving that low concentrations of the analgesics, which are detected in the influents are efficiently removed from the sewage, since the large body of the literature is concerned about the concentrations far exceeding those detected in the environment [10]. The abiotic control SWc established within this study confirmed that the removal of the analyzed drugs resulted from the biological activity of the AS microflora. Considering the NSAIDs adsorption, the sorbed pharmaceuticals onto the bacterial surface are frequently released into the medium during the long-period analysis and we did not observe such a phenomenon. The biodegradation hypothesis is also further supported by secondary metabolites formation detected by UHPLC MS/MS. A similar conclusion was made by Almeida et al. [44] who investigated the degradation of the NSAIDs mixture by the AS from three different WWTPs. Generally, the biodegradation kinetics in the bioaugmented assay AS1 and the non-bioaugmented AS2 followed a similar trend, especially for APAP, which was utilized with equal efficiency in both systems. Efficient biodegradation of APAP, the monocyclic analgesic with relatively simple chemical structure was expected in both the bioaugmented and non-bioaugmented systems. Similar observations were made by De Gusseme et al. [49] who demonstrated that after 16 days of operation at a hydraulic retention time of 5 days in a membrane bioreactor, upward of $99.9 \%$ removal of the administered dose of APAP $\left(100 \mu \mathrm{g} \mathrm{L}^{-1}\right)$ was obtained. The established microbial consortium was also able to degrade APAP at an environmentally relevant concentration of $8.3 \mu \mathrm{g} \mathrm{\textrm {L } ^ { - 1 }}$. Moreover, under the batch incubation conditions with heat-killed microorganisms the biological removal of APAP has been confirmed since its sorption to the biomass was negligible. In comparison, IBU with a high branch structure and the presence of substitutions at the para position of the aromatic ring is found as more resistant to biodegradation than APAP [50,51]. In this study, any significant changes in the removal of tested pharmaceuticals between microorganisms in the AS1 and AS2 assays were observed. Physicochemical properties of IBU molecule may determine its relatively high mobility in waters but, in comparison with other pharmaceuticals, its persistence may be lower [52]. Considering our results, this hypothesis is more probable. For IBU, the AS autochthonous microflora was equally able to metabolize IBU at the chosen concentration. Similar results were obtained by Almeida et al. [44] who investigated the degradation of IBU at the concentration of $0.5-1.0 \mathrm{mg} \mathrm{L}^{-1}$ by the AS derived from three different municipal WWTPs. For DCF, to date, only a few reports about degradation have been published, e.g., by attached growth biomass from a carrier-filled compartment of a hybrid bioreactor at the WWTP, microbial removal investigated in a MBR, or DCF removal by microorganisms from agricultural soils [53-55], however, microorganisms responsible for its biodegradation have not been identified. As a consequence, limited information regarding microorganisms responsible for DCF utilization and microbial processes underlying the degradation of its residues are available. The sensitivity of microorganisms to this compound could be partly responsible for the harmful effects of DCF and/or DCF-containing mixtures on the microbial biodiversity in the AS. Jewell et al. [56] revealed $88 \%$ removal of the initial concentration of DCF $\left(1.6 \mu \mathrm{g} \mathrm{L}^{-1}\right)$ in the influent of the full-scale WWTP during 10-day monitoring experiment and confirmed the formation of several by-products. In this study, significant differences in DCF removal were found between the bioaugmented assay AS1 and non-bioaugmented AS2. It was probably caused by the inoculation of the AS with P. moorei KB4 strain, which can metabolize relatively high concentrations of DCF. For NPX, the second analyzed polycyclic NSAIDs, the dynamics rates were quite similar for the AS1 and AS2 assays. Considering its high resistance to the biological treatment, extremely limited knowledge about degradation pathways and microorganisms capable of degrading this NSAID, the bioaugmentation strategy may be a promising tool for the successful removal of NPX in wastewater [57]. Despite the relatively large release of the analyzed pharmaceuticals into the environment, the knowledge about the metabolic pathways of their degradation remains still not fully understood. The partial metabolic pathways and key metabolites 
formed during the degradation of tested pharmaceuticals by bacterial strains used in the consortium were established in the previous studies $[31,51,58]$. For APAP, the two most frequently detected microbial metabolites include hydroquinone and 4-aminophenol [21,31,59,60]. In this study, in the assay AS1 both metabolites were identified and efficiently removed by the AS communities. For IBU, the hydroxy- and carboxyibuprofen derivatives are described as the most commonly detected in the WWTPs effluents [61]. The formation of both 1-OH-IBU and 2-OH-IBU metabolites were observed in the AS1 assay, although, the analysis performed with the use of UHPLC MS/MS revealed that both metabolites were efficiently degraded. Over 30 days of treatment, the accumulation of 2-OH-IBU in the AS1 was observed at $t_{21}$, however, its presence was not further revealed $\left(t_{30}\right)$. The accumulation of $O$-desmethylnaproxen, a key by-product of NPX degradation, identified e.g., for $B$. thuringiensis B1(2015b) [58], was excluded by the UHPLC MS/MS analysis. For DCF, 4-OH-DCF and lactam DCF are known as one of the most important initially formed secondary metabolites during microbial degradation [56]. The constant presence of 4-OH-DCF was confirmed in the AS1 assay using the UHPLC MS/MS with the highest value at $t_{21}$. Noteworthy, after every 7 days of the AS1 assay operation, none of the tested drugs were found. Moreover, further analysis confirmed that key by-products were metabolized by the same microorganisms, which clearly indicated that examined drugs at low concentrations as well as their key metabolites were not accumulated. Considering that most of the organic pollutants and their by-products are characterized by high toxicity and chemical stability, from the environmental point of view biodegradation of the mature compound and its metabolites is extremely beneficial.

\subsection{Isolation of New DCF-Degrading Strains}

The novelty of this work relates also to the isolation of two new bacterial strains Serratia proteamaculans AS4 and Rahnella bruchi AS7 able to DCF degrade. Although the 16S rRNA sequence is widely used to establish the taxonomy of the newly isolated strains due to its high conservation, failing to provide proper phylogenetic resolution to assigned analyzed strains to the level of species [62,63]. Thus, MLST analysis performed in this study based on the two additional genes provided better discrimination of the phylogenetic analysis. To date, only a few DCF-metabolizing bacterial strains have been isolated, e.g., Enterobacter hormachei D15 [42], Raoultella sp. DD4 [64], Brevibacterium sp. D4 [65], Raoultella sp. KDF8 [66], Labrys portucalensis F11 [67], and Klebsiella sp. KSC [68]. The ability of new isolates to degrade DCF were studied under the co-metabolic conditions with glucose, because none of them were able to metabolize DCF as a sole carbon and energy source. Supplementation with the additional carbon source frequently ensures the increase in the bacterial biomass and, simultaneously, better degradation of the drug [29]. Similarly, glucose as an external carbon source applied by Aissaoui et al. [42] under co-metabolic degradation of DCF by Enterobacter hormaechei D15 strain significantly intensified biodegradation efficiency. In turn, Moreira et al. [67] intensified biodegradation of DCF by Labrys portucalensis F11 strain by periodic feeding with sodium acetate, which allowed to obtain higher bacterial density. In this study, S. proteamaculans AS4 and R. bruchi AS7 were able to degrade almost $0.5 \mathrm{mg} \mathrm{L}^{-1}$ of DCF which definitely exceeds the detected environmental concentrations of this drug.

\section{Conclusions}

The AS technology is an effective method for treating the wastewater containing selected monoand polycyclic NSAIDs and/or analgesics. The bioaugmentation of the AS with bacterial strains with naturally increased degradative capabilities seems to be a promising solution for the removal of poorly biodegradable pharmaceuticals e.g., DCF and NPX. In this study, the addition of the designed microbial consortium consisting of three pharmaceuticals-degrading strains did not cause any severe changes in the biomass and metabolic activity of the AS microorganisms. Moreover, in the metabolic properties of the autochthonous microflora any significant changes were not found. Nevertheless, the introduced strains intensified the metabolism of different groups of substrates compared to the non-bioaugmented 
AS. Throughout the experiment, we identified a few key secondary metabolites including hydroxylated derivatives of IBU and DCF. Additionally, two new DCF-degrading isolates were obtained from the non-bioaugmented AS, namely Serratia proteamaculans AS4 and Rahnella bruchi AS7.

Supplementary Materials: The following are available online at http://www.mdpi.com/2073-4441/12/4/1133/s1, Table S1: The electrospray mode of the analyzed compounds and transition of $\mathrm{m} / \mathrm{z}$ of precursors to $\mathrm{m} / \mathrm{z}$ of products.

Author Contributions: Conceptualization, J.Ż., A.N.; methodology, J.Ż., A.N., J.M., A.P.; software, J.Ż., A.N., J.M., A.P.; validation, J.Ż., A.N., formal analysis, A.M.; investigation, J.Ż., A.N., A.P.; data curation, J.Ż., A.N., J.M., A.P.; writing—original draft preparation, J.Ż., A.N., J.M.; writing—review and editing, A.M.; visualization, J.Ż., A.N., J.M., A.P., supervision, J.Ż., A.N., A.M.; project administration, J.Ż., A.N.; funding acquisition, J.Ż. All authors have read and agreed to the published version of the manuscript.

Funding: This research was funded by the Ministry of Science and Higher Education and realized under the Intelligent Development Operational Program (2014-2020), grant number 8/NAB3/II+/2017.

Conflicts of Interest: The authors declare no conflict of interest.

\section{References}

1. Benotti, M.J.; Brownawell, B.J. Microbial degradation of pharmaceuticals in estuarine and coastal seawater. Environ. Pollut. 2009, 157, 994-1002. [CrossRef] [PubMed]

2. Kim, S.; Chu, K.H.; Al-Hamadani, Y.A.J.; Park, C.M.; Jang, M.; Kim, D.-H.; Yu, M.; Heo, J.; Yoon, Y. Removal of contaminants of emerging concern by membranes in water and wastewater: A review. Chem. Eng. J. 2018, 335, 896-914. [CrossRef]

3. Roberts, P.H.; Thomas, K.V. The occurrence of selected pharmaceuticals in wastewater effluent and surface waters of the lower Tyne catchment. Sci. Pollut. Res. 2006, 356, 143-153. [CrossRef] [PubMed]

4. Esterhuizen-Londt, M.; Schwartz, K.; Pflugmacher, S. Using aquatic fungi for pharmaceutical bioremediation: Uptake of acetaminophen by Mucor hiemalis does not result in an enzymatic oxidative stress response. Fungal Biol. 2016, 120, 1249-1257. [CrossRef] [PubMed]

5. Guerra, P.; Kim, M.; Shah, A.; Alaee, M.; Smyth, S.A. Occurrence and fate of antibiotic, analgesic/anti-inflammatory, and antifungal compounds in five wastewater treatment processes. Sci. Total Environ. 2014, 473, 235-243. [CrossRef]

6. Luo, Y.; Guo, W.; Ngo, H.H.; Nghiem, L.D.; Hai, F.I.; Zhang, J.; Liang, J.; Wang, X. A review on the occurrence of micropollutants in the aquatic environment and their fate and removal during wastewater treatment. Sci. Total Environ. 2014, 473-474, 619-641. [CrossRef]

7. Matongo, S.; Birungi, G.; Moodley, B.; Ndungu, P. Pharmaceutical residues in water and sediment of Msunduzi River, Kwa Zulu-Natal, South Africa. Chemosphere 2015, 134, 133-140. [CrossRef]

8. Ashfaq, M.; Noor, N.; Saif-Ur-Rehman, M.; Sun, Q.; Mustafa, G.; Nazar, M.F.; Yu, C.-P. Determination of commonly used pharmaceuticals in hospital waste of Pakistan and evaluation of their ecological risk assessment. Clean Water Air Soil 2017, 45, 1500392. [CrossRef]

9. Tiwari, B.; Sellamuthu, B.; Ouarda, Y.; Drogui, P.; Tyagi, R.D.; Buelna, G. Review on fate and mechanism of removal of pharmaceutical pollutants from wastewater using biological approach. Bioresour. Technol. 2017, 224, 1-12. [CrossRef]

10. Żur,J.; Piński, A.; Marchlewicz, M.; Hupert-Kocurek, K.; Wojcieszyńska, D.; Guzik, U. Organic micropollutants paracetamol and ibuprofen-Toxicity, biodegradation, and genetic background of their utilization by bacteria. Environ. Sci. Pollut. Res. 2018, 25, 21498-21524. [CrossRef]

11. Falås, P.; Baillon-Dhumez, A.; Andersen, H.R.; Ledin, A.; la Cour Jansen, J. Suspended biofilm carrier and activated sludge removal of acidic pharmaceuticals. Water Res. 2012, 46, 1167-1175. [CrossRef] [PubMed]

12. Festa, S.; Coppotelli, B.M.; Morelli, I.S. Comparative bioaugmentation with a consortium and a single strain in a phenanthrene-contaminated soil: Impact on the bacterial community and biodegradation. Appl. Soil Ecol. 2016, 98, 8-19. [CrossRef]

13. Loperana, L.; Saravia, V.; Murro, D.; Ferrari, M.D.; Lareo, C. Kinetic properties of a commercial and a native inoculum for aerobic milk fat degradation. Bioresour. Technol. 2006, 97, 2160-2165. [CrossRef] [PubMed] 
14. Loperana, L.; Ferrari, M.D.; Saravia, V.; Murro, D.; Lima, C.; Ferrando, L.; Fernández, A.; Lareo, C. Performance of a commercial inoculum for the aerobic biodegradation of a high fat content dairy wastewater. Bioresour. Technol. 2007, 98, 1045-1051. [CrossRef] [PubMed]

15. Singer, A.C.; van der Gast, C.J.; Thompson, I.P. Perspectives and vision for strain selection in bioaugmentation. Trends Biotechnol. 2005, 23, 74-77. [CrossRef] [PubMed]

16. Michalska, J.; Greń, I.; Żur, J.; Wasilkowski, D.; Mrozik, A. Impact of the biological cotreatment of the Kalina Pond leachate on laboratory sequencing batch reactor operation and activated sludge quality. Water 2019, 11, 1539. [CrossRef]

17. Hernandez-Raquet, G.; Durand, E.; Braun, F.; Cravo-Laureau, C.; Godon, J.-J. Impact of microbial diversity depletion on xenobiotic degradation by sewage-activated sludge. Environ. Microbiol. Rep. 2013, 4, 588-594. [CrossRef]

18. Domaradzka, D.; Guzik, U.; Wojcieszyńska, D. Biodegradation and biotransformation of polycyclic non-steroidal anti-inflammatory drugs. Rev. Environ. Sci. Biotechnol. 2015, 14, 229-239. [CrossRef]

19. Thompson, I.P.; Van Der Gast, C.J.; Ciric, L.; Singer, A. Bioaugmentation for bioremediation: The challenge of strain selection. Environ. Microbiol. 2005, 7, 909-915. [CrossRef]

20. Nzila, A.; Razzak, S.A.; Zhu, J. Bioaugmentation: An emerging strategy of industrial wastewater treatment for reuse and discharge. Int. J. Environ. Res. Public Health 2016, 13, 846. [CrossRef]

21. Zhang, L.; Hu, J.; Zhu, R.; Zhou, Q.; Chen, J. Degradation of paracetamol by pure bacterial cultures and their microbial consortium. Appl. Microbiol. Biotechnol. 2013, 97, 3687-3698. [CrossRef] [PubMed]

22. Kolvenbach, B.A.; Helbling, D.E.; Kohler, H.-P.E.; Corvini, P.F.-X. Emerging chemicals and the evolution of biodegradation capacities and pathways in bacteria. Curr. Opin. Biotechnol. 2014, 27, 8-14. [CrossRef] [PubMed]

23. Li, Z.; McLachlan, M.S. Biodegradation of chemicals in unspiked surface waters downstream of wastewater treatment plants. Environ. Sci. Technol. 2019, 53, 1884-1892. [CrossRef]

24. APHA. Standard Methods for the Examination of Water and Wastewater; American Public Health Association, American Water Works Association, Water Environment Federation: Washington, DC, USA, 1999.

25. Miksch, K. Application of dehydrogenase activity determinations in biodegradation of refinery sewage. Gas Water Civ. Technol. 1977, 51, 234-235.

26. Schumacher, T.E.; Eynard, A.; Chintala, R. Rapid cost-effective analysis of microbial activity in soils using modified fluorescein diacetate method. Environ. Sci. Pollut. Res. 2015, 22, 4759-4762. [CrossRef] [PubMed]

27. Lim, J.W.; Yan, J.Z.; Seng, C.E. Performance of phenol-acclimated activated sludge in the presence of various phenolic compound. Appl. Water Sci. 2013, 3, 515-525. [CrossRef]

28. EN ISO 8199:2010. Water Quality_General Requirements and Guidance for Microbiological Examinations by Culture; International Organization for Standardization: Geneva, Switzerland, 2010.

29. Marchlewicz, A.; Domaradzka, D.; Guzik, U.; Wojcieszyńska, D. Bacillus thuringiensis B1(2015b) is a Gram-positive bacteria able to degrade naproxen and ibuprofen. Water Air Soil Pollut. 2016, 227, 197. [CrossRef]

30. Guzik, U.; Greń, I.; Wojcieszyńska, D.; Łabużek, S. Isolation and characterization of a novel strain of Stenotrophomonas maltophilia possessing various dioxygenases for monocyclic hydrocarbon degradation. Braz. J. Microbiol. 2009, 40. [CrossRef]

31. Żur, J.; Wojcieszyńska, D.; Hupert-Kocurek, K.; Marchlewicz, A.; Guzik, U. Paracetamol—Toxicity and microbial utilization. Pseudomonas moorei KB4 strain as a case study for exploring degradation pathway. Chemosphere 2018, 206, 192-202. [CrossRef]

32. Wojcieszyńska, D.; Guzik, U.; Greń, I.; Perkosz, M.; Hupert-Kocurek, K. Induction of aromatic ring: Cleavage dioxygenases in Stenotrophomonas maltophilia strain KB2 in cometabolic systems. World J. Microbiol. Biotechnol. 2011, 27, 805-811. [CrossRef]

33. Miksch, $\mathrm{K}$. The influence of the concentration of dissolved oxygen on the determination of the dehydrogenase activity of activated sludge using method of TTC test. Clean Soil Air Water. 1983, 11, 17-21. [CrossRef]

34. Nowak, A.; Mrozik, A. Degradation of 4-chlorophenol and microbial diversity in soil inoculated with single Pseudomonas sp. CF600 and Stenotrophomonas maltophilia KB2. J. Environ. Manag. 2018, 215, 216-229. [CrossRef] [PubMed]

35. Wu, M.; Eisen, J. A simple, fast, and accurate method of phylogenomic inference. Genome Biol. 2008, 9, R151. [CrossRef] [PubMed] 
36. Wattam, A.R.; Davis, J.J.; Assaf, R.; Boisvert, S.; Brettin, T.; Bun, C.; Conrad, N.; Dietrich, E.M.; Disz, T.; Gabbard, J.L.; et al. Improvements to PATRIC, the all-bacterial bioinformatics database and analysis resource center. Nucl. Acid Res. 2017, 45, 535-542. [CrossRef] [PubMed]

37. Rozas, O.; Vidal, C.; Baeza, C.; Jardim, W.F.; Rossner, A.; Mansilla, H.D. Organic micropollutants (OMPs) in natural waters: Oxidation by $\mathrm{UV} / \mathrm{H}_{2} \mathrm{O}_{2}$ treatment and toxicity assessment. Water Res. 2016, 98, 109-118. [CrossRef] [PubMed]

38. Grujíć, S.; Vasiljević, T.; Laušević, M. Determination of multiple pharmaceutical classes in surface and ground waters by liquid chromatography-ion-trap-tandem-mass spectrometry. J. Chromatogr. A 2009, 1216, 4989-5000. [CrossRef]

39. Paxéus, N. Removal of selected non-steroidal anti-inflammatory drugs (NSAIDs), gemfibrozil, carbamazepine, $\beta$-blockers, trimethoprim and triclosan in conventional wastewater treatment plants in five EU countries and their discharge to the aquatic environment. Water Sci. Technol. 2004, 50, 253-260. [CrossRef]

40. Quintana, J.B.; Weiss, S.; Reemtsma, T. Pathways and metabolites of microbial degradation of selected acidic pharmaceutical and their occurrence in municipal wastewater treated by membrane bioreactor. Water Res. 2005, 39, 2654-2664. [CrossRef]

41. Salgado, R.; Marques, R.; Noronha, J.P.; Carvalho, G.; Oehmen, A.; Reis, M.A. Assessing the removal of pharmaceuticals and personal care products in a full-scale activated sludge plant. Environ. Sci. Pollut. Res. Int. 2012, 19, 1818-1827. [CrossRef]

42. Aissaoui, S.; Ouled-Haddar, H.; Sifour, M.; Harrouche, K.; Sghaier, H. Metabolic and co-metabolic transformation of diclofenac by Enterobacter hormachei D15 isolated from activated sludge. Curr. Microbiol. 2016, 74, 381-388. [CrossRef]

43. Jiménez-Silva, V.A.; Santoyo-Tepole, F.; Ruiz-Ordaz, N.; Galíndez-Mayer, J. Study of the ibuprofen impact on wastewater treatment mini-plants with bioaugmented sludge. Process Saf. Environ. 2019, 123, 140-149. [CrossRef]

44. Almeida, B.; Oehmen, A.; Marques, R.; Brito, D.; Carvalho, G.; Barreto Crespo, M.T. Modelling the biodegradation of non-steroidal anti-inflammatory drugs (NSAIDs) by activated sludge and a pure culture. Bioresour. Technol. 2013, 133, 31-37. [CrossRef] [PubMed]

45. Reardon, K.F.; Mosteller, D.C.; Rogers, J.B.; Du Teau, N.M.; Kim, K.H. Biodegradation kinetics of aromatic hydrocarbon mixtures by pure and mixed bacterial cultures. Environ. Health Perspect. 2002, 6, 1005-1011. [CrossRef] [PubMed]

46. Xia, Y.; Wen, X.; Zhang, B.; Yang, Z. Diversity and assembly patterns of activated sludge microbial communities: A review. Biotechnol. Adv. 2018, 36, 1038-1047. [CrossRef]

47. Hailei, W.; Ping, L.; Ying, W.; Lei, L.; Jianming, Y. Metagenomic insight into the bioaugmentation mechanism of Phanerochaete chrysosporium in an activated sludge system treating coking wastewater. J. Hazard. Mater. 2017, 321, 820-829. [CrossRef]

48. Hu, J.; Yang, Q.; Wang, J.L. Biodegradation of di- $n$-butyl phthalate in sequencing batch reactor bioaugmented with Micrococcus sp. and the bacterial community analysis. Int. J. Environ. Sci. Technol. 2015, 12, 2819-2828. [CrossRef]

49. DeGusseme, B.; Vanhaecke, L.; Verstraete, W.; Boona, N. Degradation of acetaminophen by Delftia tsuruhatensis and Pseudomonas aeruginosa in a membrane bioreactor. Water Res. 2011, 45, 1829-1837. [CrossRef]

50. Musson, S.E.; Campo, P.; Tolaymat, T.; Suidan, M.; Townsend, T.G. Assessment of the anaerobic degradation of six active pharmaceutical ingredients. Sci. Total. Environ. 2010, 408, 2068-2074. [CrossRef]

51. Marchlewicz, A.; Guzik, U.; Smułek, W.; Wojcieszyńska, D. Exploring the degradation of ibuprofen by Bacillus thuringiensis B1(2015b): The new pathway and factors affecting degradation. Molecules 2017, 22, 1676. [CrossRef]

52. Parolini, M.; Binelli, A.; Provini, A. Chronic effects induced by ibuprofen on the freshwater bivalve Dreissena polymorpha. Ecotoxicol. Environ. Saf. 2011, 74, 1586-1594. [CrossRef]

53. Kosjek, T.; Heath, E.; Perez, S.; Petrovic, M.; Barcelo, D. Metabolism studies of diclofenac and clofibric acid in activated sludge bioreactors using liquid chromatography with quadrupole and time-of-flight mass spectrometry. J. Hydrol. 2009, 372, 109-117. [CrossRef]

54. Al-Rajab, A.J.; Sabourin, L.; Lapen, D.R.; Topp, E. The non-steroidal anti-inflammatory drug diclofenac is readily biodegradable in agricultural soils. Sci. Total Environ. 2010, 409, 78-82. [CrossRef] [PubMed] 
55. Langenhoff, A.; Inderfurth, N.; Veuskens, T.; Schraa, G.; Blokland, M.; Kujawa-Roeleveld, K.; Rijnaarts, H. Microbial removal of the pharmaceuticals compounds ibuprofen and diclofenac from wastewater. BioMed Res. Int. 2013, 2013, 325806. [CrossRef]

56. Jewell, K.S.; Falås, P.; Wick, A.; Joss, A.; Ternes, T.A. Transformation of diclofenac in hybrid biofilm activated sludge processes. Water Res. 2016, 105, 559-567. [CrossRef] [PubMed]

57. Matamoros, V.; Arias, C.; Brix, H.; Bayona, J.M. Preliminary screening of small-scale domestic wastewater treatment systems for removal of pharmaceutical and personal care products. Water Res. 2009, 43, 55-62. [CrossRef] [PubMed]

58. Górny, D.; Guzik, U.; Hupert-Kocurek, K.; Wojcieszyńska, D. A new pathway for naproxen utilisation by Bacillus thuringiensis B1(2015b) and its decomposition in the presence of organic and inorganic contaminants. J. Environ. Manag. 2019, 239, 1-7. [CrossRef]

59. Wu, S.; Zhang, L.; Chen, J. Paracetamol in the environment and its degradation by microorganisms. Appl. Microbiol. Biotechnol. 2012, 96, 875-884. [CrossRef]

60. Żur, J.; Piński, A.; Michalska, J.; Hupert-Kocurek, K.; Nowak, A.; Wojcieszyńska, D.; Guzik, U. A whole-cell immobilization system on bacterial cellulose for the paracetamol-degrading Pseudomonas moorei KB4 strain. Int. Biodeterior. Biodegrad. 2020, 149, 104919. [CrossRef]

61. Murdoch, R.W.; Hay, A.G. The biotransformation of ibuprofen to trihydroxyibuprofen in activated sludge by Variovorax Ibu-1. Biodegradation 2015, 26, 105-113. [CrossRef]

62. Patiño, L.H.; Camargo, M.; Muñoz, M.; Ríos-Chaparro, D.I.; Patarroyo, M.A.; Ramírez, J.D. Unveiling the Multilocus Sequence Typing (MLST) schemes and core genome phylogenies for genotyping Chlamydia trachomatis. Front. Microbiol. 2018, 9, 1854. [CrossRef]

63. Hu, Y.; Wei, L.; Feng, Y.; Xie, Y.; Zong, Z. Klebsiella huaxiensis sp. nov., recovered from human urine. Int. J. Syst. Evol. Microbiol. 2019, 69, 333-336. [CrossRef] [PubMed]

64. Domaradzka, D.; Guzik, U.; Hupert-Kocurek, K.; Wojcieszyńska, D. Toxicity of diclofenac and its biotransformation by Raoultella sp. DD4. Pol. J. Environ. Stud. 2016, 25, 2211-2216. [CrossRef]

65. Bessa, V.S.; Moreira, I.S.; Tiritan, M.E.; Castro, P.M.L. Enrichment of bacterial strains for the biodegradation of diclofenac and carbamazepine from activated sludge. Int. Biodeterior. Biodegrad. 2017, 120, 135-142. [CrossRef]

66. Palyzová, A.; Zahradník, J.; Marešová, H.; Sokolová, L.; Kyslíková, E.; Grulich, M.; Štěpánek, V.; Řezanka, T.; Kyslík, P. Potential of the strain Raoultella sp. KDF8 for removal of analgesics. Folia Microbiol. (Praha) 2018, 63, 273-282. [CrossRef]

67. Moreira, I.S.; Bessa, V.S.; Murgolo, S.; Piccirillo, C.; Mascolo, G.; Castro, P.M.L. Biodegradation of diclofenac by the bacterial strain Labrys portucalensis F11. Ecotoxicol. Environ. Saf. 2018, 152, 104-113. [CrossRef]

68. Stylianou, K.; Hapeshi, E.; Vasquez, M.; Fatta-Kassinos, D.; Vyrides, I. Diclofenac biodegradation by newly isolated Klebsiella sp. KSC: Microbial intermediates and ecotoxicological assessment. J. Environ. Chem. Eng. 2018, 6, 3242-3248. [CrossRef]

(C) 2020 by the authors. Licensee MDPI, Basel, Switzerland. This article is an open access article distributed under the terms and conditions of the Creative Commons Attribution (CC BY) license (http://creativecommons.org/licenses/by/4.0/). 